\title{
Why Do Some Grant Proposals Win the Funds and Others Fail? Genre Analysis for the Abstracts of Grant Proposals Submitted by the Health Science Center Researchers to the National Institutes of Health
}

Yassin Ismaeel

\section{Recommended Citation}

Ismaeel, Yassin, "Why Do Some Grant Proposals Win the Funds and Others Fail? Genre Analysis for the Abstracts of Grant Proposals Submitted by the Health Science Center Researchers to the National Institutes of Health" (2016). Graduate Theses, Dissertations, and Problem Reports. 5861.

https://researchrepository.wvu.edu/etd/5861

This Thesis is protected by copyright and/or related rights. It has been brought to you by the The Research Repository @ WVU with permission from the rights-holder(s). You are free to use this Thesis in any way that is permitted by the copyright and related rights legislation that applies to your use. For other uses you must obtain permission from the rights-holder(s) directly, unless additional rights are indicated by a Creative Commons license in the record and/ or on the work itself. This Thesis has been accepted for inclusion in WVU Graduate Theses, Dissertations, and Problem Reports collection by an authorized administrator of The Research Repository @ WVU. For more information, please contact researchrepository@mail.wvu.edu. 
Why Do Some Grant Proposals Win the Funds and Others Fail? Genre Analysis for the Abstracts of Grant Proposals Submitted by the Health Science Center Researchers to the National Institutes of Health

\section{Yassin Ismaeel}

Thesis submitted to the Reed College of Media at West Virginia University

$$
\begin{aligned}
& \text { in partial fulfillment of the requirements } \\
& \text { for the degree of } \\
& \text { Master of Science } \\
& \text { In } \\
& \text { Journalism }
\end{aligned}
$$

Steve Urbanski, Ph.D., Chair

Elizabeth Oppe, Ph.D.

Julia Daisy Fraustino, Ph.D.

Nathalie Singh-Corcoran, Ph.D.

Department of Journalism

Morgantown, West Virginia

2016

Keywords: fund, grant proposals, grant makers, grant seekers, genre analysis, abstracts, research articles, CARS model, movesteps, journalism, media, health communication, English for Specific Purposes

Copyright 2016 Yassin Ismaeel 


\title{
ABSTRACT \\ Why Do Some Grant Proposals Win the Funds and Others Fail? Genre Analysis for the Abstracts of Grant Proposals Submitted by the Health Science Center Researchers to the National Institutes of Health
}

\author{
Yassin Ismaeel
}

This study is an endeavor to investigate the textual linguistic factors that lead to successful grant proposals. Grant proposals have different sections. The focus was on the abstracts of grant proposals. The abstract is the first most piece read by the funding agency. There are many important contextual and situational conditions that directly affect the winning of the funds. This current study aims at the linguistic aspects of the abstracts. Twenty abstracts, chosen from the National Institutes of Health (NIH) website, were used as unit samples for the analysis. The coding units were the sentences existed in these texts. The researcher used Swales (1990) CARS model to carry out the data analysis. There were six variables used represented by the moves of this model. Due to the unique characteristics of the abstracts, some modifications were done to the model to match the nature of this genre. There were many findings, but the most significant were the order of the moves that was different from the research article introductions used by Swale's model and the focus on the aims and the significance of the grant proposal. It is expected that these linguistic features would be fed into a computer program to be used as a preliminary indicator of success for the grant writers. 


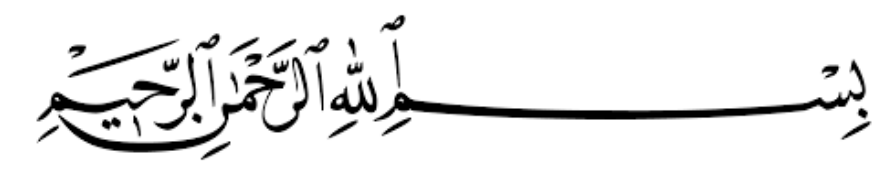

In the Name of God, Most Gracious, Most Merciful

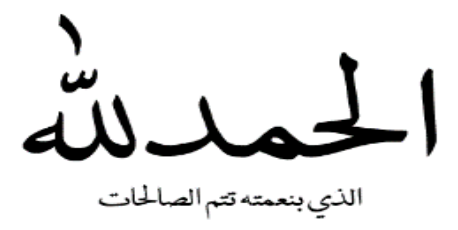

\section{Praise to God}

قال رسول الله صلى الله عليه وسلم: "إذا مات ابن آدم انقطع عمله إلا من ثلاث: صدقة جارية، أو علم ينتنفز به، أو ولد صالح بدعو له

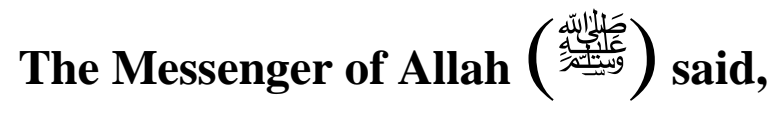

"When a man dies, his deeds come to an end except for three things: Sadaqah Jariyah (ceaseless charity); a knowledge which is beneficial, or a virtuous descendant who prays for him (for the deceased)." 


\section{Acknowledgements}

Dr. Diana Martinelli, Associate Dean at the Reed College of Media at West Virginia University is my role model. Many thanks for her kind guidance and support.

I am happy to thank Professor Anthony Billings from the Statistics Department. He was my instructor for the stat 211 class. He was very precise in his guidance with regarding to the qualitative and quantitative aspects of research. He was very helpful in determining the variable for this study.

I would like to express my gratitude to my committee chair Dr. Steve Urbanski for his patience and kindness in helping prepare all the needed requirements to pursue my master's degree.

I am grateful to my committee members: Elizabeth Oppe, Ph.D., Julia Daisy Fraustino, Ph.D., and Nathalie Singh-Corcoran, Ph.D. Their efforts and guidance helped me finish my proposal. They were very insightful and gave me a clear big picture about the steps needed to complete the whole work successfully.

I would like to thank the US Department of State for their generous scholarship that let me continue my graduate program.

Many thanks to the librarian Debby Borrelli for her kind guidance in walking me through the step by step process of the electronic submission of my thesis.

I would like to thank my mother who has been very keen to see me doing something useful for myself and for others.

I would to thank my wife for her patience and support for the time that I needed in trying to graduate and get my degree. 


\section{Table of Contents}

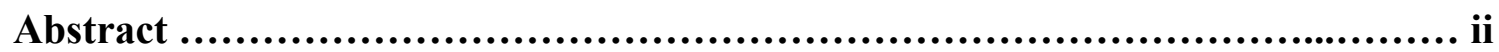

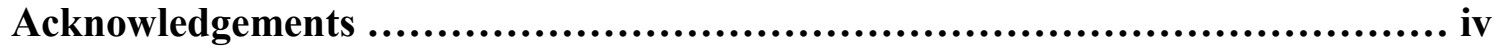

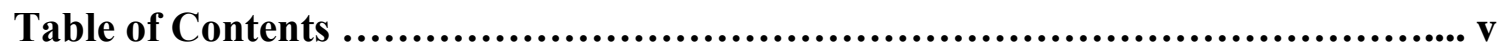

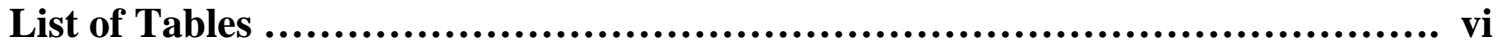

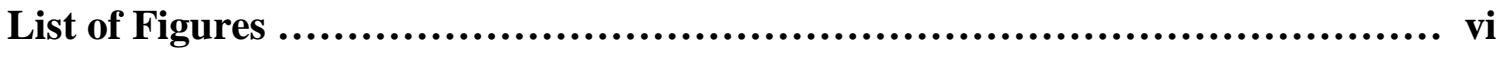

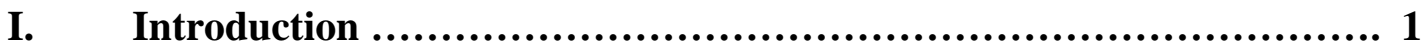

II. Background (Literature Review) $\ldots . . \ldots \ldots \ldots \ldots \ldots \ldots \ldots \ldots \ldots \ldots \ldots \ldots \ldots . . . \ldots 5$

III. Research Questions and/or Hypothesis ............................ 22

IV. Proposed Research (Materials and Methods Section) $\ldots \ldots \ldots \ldots \ldots \ldots \ldots \ldots . \ldots 23$

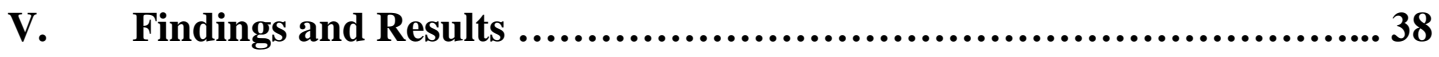

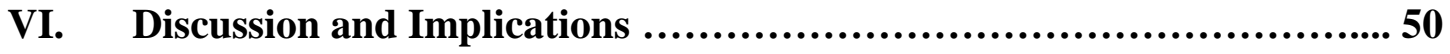

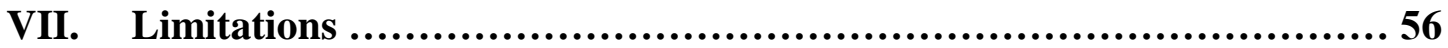

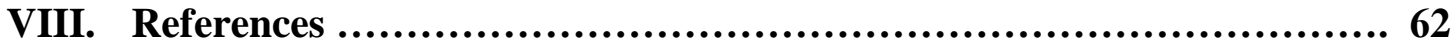

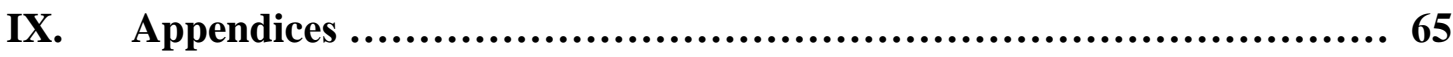




\section{List of Tables}

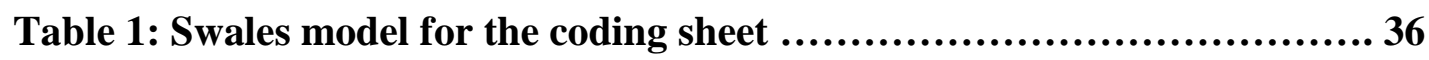

Table 2: Modified CARS model ............................................. 37

Table 3: Move structures of Twenty Abstracts .............................. 38

Table 4: Total Coded and Non-Coded Sentences in each sample unit ........... 41

Table 5: Frequency of Starting Moves in all unit samples ...................... 45

Table 6: Awards Summary by institution for Fiscal Year 2014 .................. 46

Table 7: Awards Summary by Department for Fiscal Year 2014 ................ 47

Table 8: Awards Summary by Institutions for Fiscal Year 2015 .............. 48

Table 9: Awards Summary by Department for Fiscal Year 2015 ............... 49

\section{List of Figures}

Figure 1 Swales' (1990) (CARS) model (Coding Book) ......................... 32

Figure 2: Bar Graph for the moves 1, 2, and 4 ............................. 40

Figure 3: Pie Chart for the moves 1, 2, and 4 .............................. 40

Figure 4: Total Sentences in all sample units, Total Coded Sentences, and Total Non-Coded Sentences in all sample units ......................... 43

Figure 5: Percentages of Starting Moves in all unit samples .................. 44

Figure 6: Percentages of Ending Moves in all unit samples $\ldots . \ldots \ldots \ldots \ldots \ldots \ldots \ldots \ldots . . .45$

Figure 7: Percentages of Awards Summary

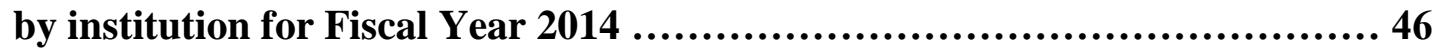

Figure 8: Awards Summary for Fiscal Year 2015 ........................... 48 


\section{GENRE ANALYSIS FOR THE ABSTRACTS OF GRANT PROPOSALS}

\section{Introduction}

Media messages are written by a variety of sources and are directed to different audiences by using different media tools. Media messages are ways of communication between a sender and a receiver. The sender tries to persuade the receiver to take a certain action or stance. In this research, grant applications are considered as media messages written by scientists from different disciplines. These applications are to persuade panels from the funding agencies that evaluate the proposals by a rigorous peer review process to grant the money for the successful applications. Buskirk and Gillen (2011) point out that "these panels are found either in companies or government bodies." They add that "the grant applications include a description of the scientists' past accomplishments and the proposed studies" (p. 85). The "abstracts" which are the most important part of these proposals, included in these applications, and their persuasive power are the focus of this thesis.

The graduate students in the Health Sciences Center at West Virginia University would like to know why some proposals succeed in getting grants while others fall short. To know why, students ought to learn that publishers, editors, and research funding sources have certain criteria to grant money to certain applications rather than others. In addition to these criteria, there are other factors that are important for the projects to get the funds. Some of these factors were suggested by Dr. Diana Martinelli, Associate Dean at the Reed College of Media at West Virginia University. She says that "successful grants depend on more than the written text, including previous grants with the agency and reputation of the researcher/institution, and conflict of interests among many others" (personal communication, August 22, 2013). This study is not going to investigate these criteria or factors; instead, this thesis will search for linguistic 


\section{GENRE ANALYSIS FOR THE ABSTRACTS OF GRANT PROPOSALS}

features that are hidden within the texts of these proposals that contribute in their persuasive power.

The focus of this thesis will be on the successful grant proposal. The success of the proposal will be the dependent variable. The independent variable for this study would be the rhetorical patterns and linguistic features that are persuasive tools and used within the context of the 'abstracts' of successful proposals. Buskirk and Gillen (2011) said: 'Dependent variables change in response to other variables... Take care to identify the dependent variables, because these are often the study's focus" (p. 94).

The theoretical background for this thesis made it hard to find similar research in media and journalism. Rhetorical styles and linguistic features as persuasive tools and their effects on the messages are within the realms of English and communication studies. Therefore, the corpus of literature is mainly found within the literature of the English Department, College of Education, and the Communication Department. College of Education studies (Swales 1981, Jogthong 2001, and Duszak 1994) use the results of similar studies to refine their teaching methods for academic writing and to do some contrastive studies. This project hypothesizes that the rhetorical patterns and linguistic features are used as persuasive tools. They are used also to empower the "abstracts" of grant proposals. "Abstracts" are the main component of messages that are generated in response to Request for Proposals (RFPs), so rhetorical patterns and linguistic features will help the proposal to succeed in being funded. It is intended for this thesis to bridge two disciplines, mass communication and medical sciences. There is a hope that this research will have a value and benefit to principal investigators, postdoctoral fellows, senior research scientists, and any health professional in improving their ability when writing their proposals to get grants. Hopefully the results of this research will be of most benefit to those who 
work in West Virginia University/Health Sciences Center (WVU/HSC), or similar-type organizations, because their proposals will be used as samples for the expected analysis.

\section{Abbreviations and Definitions of Terms}

$\underline{\text { Abbreviations }}$

CARS - Create a Research Space

ESP - English for specific purpose

$\mathrm{NIH}$ - National Institutes of Health

RAIs - Research article introductions

SBA OII- Small Business Administration: Office of Investment and Innovation SBIR·STTR - Small Business Innovation Research · Small Business Technology

Transfer

Definitions: All these definitions were written as cited from (Jogthong, 2001, pp. 6-8). Academic writing: An academic writing is a piece of writing composed for an academic purpose, for the study and distribution of knowledge of a particular subject, or field. Beside research articles, other academic writings include student essays, abstracts, laboratory reports, theses and dissertations (Jogthong, 2001, p. $6)$.

Discourse: Discourse is a general term for examples of language use, i.e. language which has been produced as an act of communication. Whereas grammar refers to the rules of a language used to form grammatical units such as clause, phrase and sentence, discourse refers to a larger unit of language such as paragraphs, conversations and interviews (Richards, Platt \& Platt, 1992).

Experimental research: Experimental research involves a strategy of investigation in 
which the researcher systematically manipulates one or more variables and measures the effect of this manipulation on the remaining variables (Davitz \& Davitz, 1996). Experimental design was not used in this study. This definition is mentioned just to remind the reader that the topic of this study and any other topic in humanities or social sciences could be investigated qualitatively or quantitatively.

Genre: Genre refers to a particular type of a written discourse made distinctive by its purpose and the discourse community for which it is intended. Examples of genres are; abstracts, grant proposals, laboratory reports, poems, letters, editorials and novels (Jogthong, 2001, p. 7).

Linguistic features: Linguistic features are forms and structures used by a writer to achieve a communicative and rhetorical purpose (ibid, p. 7).

Move: A move in genre analysis is a unit of language made by the writer and is realized by its function or the purpose for which it is used in the discourse. A move may be as short as a clause or it may be as long as several paragraphs (ibid, p.7). Move analysis: Move analysis is a study of how language made by the writer forms a meaningful unit by identifying its forms and functions in the discourse (ibid, p.7).

Quasi-experimental design: A quasi-experimental design is a research design that involves the manipulation of one or more variables with the aim of studying the effects of that manipulation on one or more other variables. But instead of conducting actual manipulation of the variable(s) which may be impossible, impractical, or unethical, the researchers rely on differences that occur naturally. They make reasonable inferences about the effects of the manipulation on the other variables by selecting equated sample and with 
adequate controls and sampling procedures (Davitz \& Davitz, 1996) (as cited from ibid p. 7). Quasi-experimental design was not used in this study. This definition is mentioned just to remind the reader that the topic of this study and any other topic in humanities or social sciences could be investigated qualitatively or quantitatively.

Research article: A research article is a published article that aims to report a study conducted by the writer(s) and to disseminate the knowledge gained from the study (ibid, p.7).

Research article introduction: A research article introduction is an introductory section of a research article. It takes the form of an extended preface in which the nature of the study to be undertaken is explained. Apart from an abstract, a research article introduction is the beginning of an article and is typically followed by method, result, discussion and conclusion sections (ibid, p. 8).

Rhetorical pattern: A rhetorical pattern or a rhetorical characteristic refers to the underlying structure of a discourse that accounts for the organization of the discourse (Richards, Platt \& Platt, 1992) (as cited in ibid, p. 8).

\section{Background (Literature Review)}

This study will use the data from a population of grant proposals. For this reason, it is vital to define the following for the purposes of it: "Grant" and "Grant Proposal."

Smith and Works (2012) define "Grant," in general, as the funding provided by a charitablegiving foundation, public charity, or government agency to a nonprofit organization that enables the nonprofit organization to perform specified activities for the common good. They explain "Grant Proposal" as the narrative description of the work that a nonprofit organization plans to undertake to fulfill both its own and the grantmaker's goals (p. 1). This narrative description of 


\section{GENRE ANALYSIS FOR THE ABSTRACTS OF GRANT PROPOSALS}

the work has an explanation of the problem to be addressed, a detailed plan for addressing the problem, what it will cost, and what results the grantmaker can expect from the proposed project or initiative.

Reactive grant seeking is issued as a response to "Request for Proposal (RFP)", and such grants require strong analytical reading and good writing skills, while proactive grants need a well-planned strategy and knowledge of the potential donor sources and their interests and motivations for funding. Whether the grant is reactive or proactive, successful grant seeking requires more than writing skills alone. Smith and Works (2012) note that good grant writers must also be good strategic planners, analytic readers, masters of basic accounting principles, and perpetual students in the field (p. 3). However, this study will focus on reactive grants as they count heavily on good writing skills. The grant author's positive persuasive words are supposed to have a similar effect on the reviewers of the proposals.

Grant writing is a genre by itself. Merriam-Webster Dictionary defines genre as a particular type or category of literature, art, or music whose composition is characterized by a particular style, form, or content. There are many definitions for the word genre.

Swales (1990) said that a genre comprises a class of communicative events, the members of which share some set of communicative purposes. These purposes are recognized by the expert members of the parent discourse community, and thereby constitute the rationale for the genre. This rationale shapes the schematic structure of the discourse and influences and constrains choice of content and style (p. 58).

This definition made clear that the genres are types of goal-directed communicative events that have schematic structures and most strikingly genres are disassociated from registers or styles (ibid, p. 42). Paltridge (2011) simply stated that genres are specific texts. He added that each 


\section{GENRE ANALYSIS FOR THE ABSTRACTS OF GRANT PROPOSALS}

genre has typical discourse patterns that includes how the texts are typically organized, how the texts are typically presented in terms of layout and format, and the language features that typically re-occur in the particular genre. Zhou and Sloan (2009) defined genres as large groups of texts that have similar elements (p. 316). Jogthong (2001) cited a summarized version for the definition of genre. He stated that genre refers to a particular type of a written discourse made distinctive by its purpose and the discourse community for which it is intended. He said examples of genres are: abstracts, grant proposals, laboratory reports, poems, letters, editorials, and novels (p. 7). The author of this current study found that genre is a topic that is deeply rooted in Literary Studies.

This thesis will study "Grant Writing” in English. Theoretically and practically speaking, there are constraints and limits on textual and contextual features of writing a grant proposal. Paltridge and Starfield (2012) point out clearly "Genre studies in 'English for Specific Purpose (ESP)' then, have increasingly moved from linguistic descriptions, of their own, to studies which aim to understand why genres are shaped as they are, and how they achieve their particular goals" (p. 349). This indicates that winning a grant is difficult but not impossible. By mastering the necessary aspects of writing the proposal, winning will be a possible logical outcome.

Winning a grant is not an easy process. There is an intense struggle in this marathon. Khadka (2014) explains "The struggle metaphor explains the force and dilemma existing in the production and reception of the grant genre" (p. 261). He then suggests "The struggle, for instance, in research grant proposal, is between the writer and her/his co-participants—funding agencies, proposal reviewers, and fellow researchers, or even her own personal wishes or goals such as gaining recognition or furthering a career" (ibid). Writing and winning the grant proposal is a multifactorial and very sophisticated process. Different parameters and criteria play part in 


\section{GENRE ANALYSIS FOR THE ABSTRACTS OF GRANT PROPOSALS}

the outcome. For the sake of this discussion, it is worth to mention three important aspects that should be taken into consideration by the writer of the grant proposal. Nelson, Titsworth, and Pearson (2012) explained that the ancient Greek philosopher Aristotle noticed three areas in any persuasive communication message. He called them ethos, logos, and pathos. They could be defined in brief as follows: Ethos is the source's (writer's) credibility, trustworthiness, dynamism, or competence; Pathos is the use of emotions to motivate the audience; and Logos is the use of logical argument. Integrating all these three forms of proof is an art conducted by the writer (source) of the persuasive communication message (pp. 16 and 32). These three sources of appeal described by Aristotle can provide a useful lens for this current study. Grant proposals are persuasive communication messages by themselves. The grant seekers are the sources of these messages, so grant writers better to be armed and effectively apply these three aspects of rhetoric.

\section{Funding Agencies Effect (audience, receiver, pathos, emotions)}

Even if research teams in the HSC might use research assistants from different disciplines, who had some experience in writing proposals, these messages would be directed to specific audience, who are the panel members of the funding agencies. Dr. Martinelli, (personal communication, August 22, 2013) states that "Grant proposals are written to address the needs of the funding agency (most are very specific; regarding the kind of information they ask grant seekers to provide). Therefore, the proposals are intended for a very specific audience-the same audience who requested the response." The specificity of the audience will be related to the contextual feature of this genre and it is outside the scope of this study.

Through their selective funding of research projects, some funding organizations exert influence on medical research in universities. Only research proposals promising lucrative (i.e. 


\section{GENRE ANALYSIS FOR THE ABSTRACTS OF GRANT PROPOSALS}

producing a great deal of profit) results are given serious consideration, and funding is usually awarded to scientists at large institutions that already have vast research experience (Kaplan Test Prep, 2012, p. 68). Thus, only larger universities will be able to continue developing adequate research facilities, and graduate students will learn that their future research must conform to the expectations of the funding corporation. Research sometimes continue to be conducted at the expense of human welfare (Kaplan Test Prep, 2012, p. 69). There is a study done by a master student in San Diego State University that tackled pathos aspects of the grant writing process.

Stringfield (2013) carried out interviews with a convenience sample of interviewees from grant making organizations in San Diego (p. 6). She divided the interview questionnaire into groups that matched the different sections of the grant applications under investigation. She assigned the persuasive modes: ethos, pathos, and logos to these questions. These assignments were vetted by a small focus group of business and philosophy specialists to substantiate the researcher's assignment of these items. She assigned only one mode to each question. She pointed out that multiple modes might be assigned to certain questions (p. 8). Her work dealt with the whole sections of the grant application and focused on the grant maker's side. Her work also didn't study the product of the grant seekers, which is the text of the grant application itself. This current study will focus on the text of the grant application, which is the product of the grant seeker. Specifically, the author will put the abstract section of the grant proposal (application) under microscope. The abstract is considered the most important part of the grant application and gives a hint about all its other sections. Therefore, the fund seeker and the text produced are other aspects that should be considered in addition to the funding agencies as factors that may become a reason in winning the fund. 
GENRE ANALYSIS FOR THE ABSTRACTS OF GRANT PROPOSALS

\section{Grant Seekers Effect (author, sender, ethos, credibility)}

Many other sources point out that many factors, other than the textual features, affect the success of the grant proposal. Dr. Martinelli remarks that "successful grants depend on more than the written text, including previous grants with the agency and reputation of the researcher/institution" (Diana Martinelli, Associate Dean at the Reed College of Media at West Virginia University, personal communication, August 22, 2013). Dr. Martinelli is right because winning reactive grant proposals is greatly affected by the audience who are the reviewers in this case. Although the RFP will clearly state what the audience (reviewers) wants to know and in what order, the grantwriter is responsible to learn as much as possible about who will be reading and judging their proposal. As was mentioned above, Stringfield (2013) studied also the ethos aspects that contribute to the persuasive argument structure (p. 8).

\section{How can we extract the Effects of the Textual Features? (text, message, logos, logic)}

For the above-mentioned reasons, all the other factors that could affect the outcome or the reviewers should be controlled to validate the results of this research. So, the only point, criterion, or difference that should be left under study will be the textual features of the successful grant proposals. Grant proposal texts and logical arguments presented within these texts (messages) constitutes the logo appeal for the Aristotle's rhetorical appeals that are default in any kind of communication (Nelson et al. 2012, p. 16). Dadisman (2011) cited that rhetorical appeals of reason considered what information and arguments have been or could be made about a topic and this is called logical appeal or $\log$ os (p. 30). Rhetorical appeals of style on the other hand consider the what metaphors, images, oppositions, and form or arrangement used to make the text an effective persuasive message (ibid, p. 30). So, the textual, linguistic, and stylistic features can be done either through performing critical analysis to determine which data set (and 


\section{GENRE ANALYSIS FOR THE ABSTRACTS OF GRANT PROPOSALS}

conclusion) was obtained in the most legitimate, unbiased way or through an experiment, observation and data analysis (MCAT Physics and Math Review, pp. 366-367). For this thesis, genre analysis will be performed on successful grant proposals to determine if they are similar or different in their textual features.

Literature is readily available about learning how to write and find grant proposals, proper planning and where to apply, and how to avoid common mistakes and pitfalls; however, the literature is almost scarce or negligible in providing us with tools of how to measure the effectiveness of the final product. In other words, there are no studies conducted to determine the criteria by which a grant writer can have an idea about his project before he submits it to the reviewers to give their final decision of getting or denying the fund. This research is trying to fill this gap in scholarship.

Dr. Nathalie Singh-Corcoran, Ph.D. Department of English at West Virginia University (personal communication, September 2, 2015) agrees with the idea of this work and expects practical benefits. She says that choosing content analysis, or a derivative of it as 'quantitative genre analysis' as it is expected for this thesis, as a method and finding out quantitatively the persuasive tools used by authors in the text of the grant proposals will generate database. This data-base could be fed into a computer program that could be used to give a preliminary indicator for the success of a proposal before the grant seeker submits it. This notion goes along with the theory proposed by Paltridge and Starfield (2012): "At the same time, textual analyses have moved, increasingly, from being "done by hand" to being computer-assisted, allowing for analyses to be based on a larger set of texts and, thereby, providing greater generalizability of the results" (p. 349). Dr. Elizabeth Oppe (personal communication, April 13 ${ }^{\text {th }}, 2016$ ) said that the results of this work could be simply compared to LSAT or any other standard admission test. By 
GENRE ANALYSIS FOR THE ABSTRACTS OF GRANT PROPOSALS

taking high scores in this test program, the grant seeker can have an indication of whether his/her application will win the grant or not. Grant proposals, as a text, have many sections.

\section{Grant Proposals Sections:}

The grant proposal has five main components in addition to some others. Smith and Works (2012) mentioned most grant proposals, whether reactive or proactive, contain five core sections: An abstract or executive summary, the statement of need or problem, the project description, an evaluation plan, and a budget (p. 73). These sections are not equal in value and the impression on the part of the reviewers is different from each of these sections. The executive summary (also called an abstract) can vary in length from one paragraph to one or two pages (ibid, p. 73). “The executive summary is your reader's first impression of the work. To make a good impression and leave the reader eager to read the body of the proposal, craft this section carefully. Pull out the most salient information and highlight the strength of your project and organization" (Smith \& Works, 2012, p. 74). With that being said, the executive summary will have the "textual features" including the positive and negative author words. Therefore, the focus of the quantitative genre analysis will be done in this study on the stylistic and textual features of the "abstract" of the proposals. Smith and Works also explained:

The primary points in the executive summary will succinctly cover the other four basic sections of the grant proposal. Discuss the need or problem, the approach you will take or other key information from the project description, how you'll evaluate the program, and what it will cost. You'll introduce your organization, state your grant request, and discuss how the project meets the grant maker's stated goals (p. 74). 


\section{GENRE ANALYSIS FOR THE ABSTRACTS OF GRANT PROPOSALS}

Locke et al. (2014) confirmed that the abstracts are very important for the reviewers. He stated that the reviewers may not see more of a given proposal than the cover sheets, the abstract, the author's vita, and perhaps the budget. That prospect should be sufficient to encourage attention to producing the best possible abstract (p. 214). Booth et al (2008) said, in their discussion of warrants in everyday reasoning that even in research "when readers find an error in one bit of evidence, they distrust the rest" (p. 154). This argument suggested that if something wrong with the abstract, the reviewers or professional evaluators would suspect the whole other sections of the grant application. The researcher thought of the abstract as the diagnostic tool for the general health of the project or grant application.

It is clear now why the "abstract" of the "grant proposals" will be used in this study. Jogthong (2001), in his work on research article introductions, suggested that further studies may also include the analysis of other equally important genres such as grant proposals (p. 90). This study uses the framework of research article introduction strategy to apply it on the grant proposal analysis.

\section{Finding the appropriate theory and methodology for this work:}

One of the main challenges of this thesis is finding the appropriate theory/literature and methodology that goes along with the intention and goals of the investigation. This challenge arises because the researcher does not start by choosing well-established research and trying to replicate it. Paltridge and Starfield (2012) explain that graduate students need to look at theses written in their subject area and see how they are structured. They add that graduate students would examine previous theses to find out what conventions exist within their own discipline and to find out how binding those conventions are (p. 290). As it is mentioned in the introduction, the investigator visited the Health Science Center at WVU to ask about the problem 


\section{GENRE ANALYSIS FOR THE ABSTRACTS OF GRANT PROPOSALS}

they have had and try to solve it through research. It was expected that this would have led to a more creative study. However, it turns out that it is hard for the professors whether in medical field or in journalism and mass communication to help in giving guidelines about the theory, data needed, or the appropriate research method to be used. There is no blame on these professors. In social sciences studies, as Paltridge and Starfield (2012) confirm "In an arts or social science discipline, by contrast to science subject, the student may be expected to exercise greater independence" (p. 290). Booth et al (2008) said "A downside of academic research is its isolation. Except for group projects, you'll read and write mostly alone" (p. 34). It turned out for the author of this thesis that finding a theory was not easy process exactly like when somebody wanted to choose a topic for a research. Booth et al (2008) argued that if you were free to research any topic that interested you, that freedom might seem frustrating — so many choices, so little time (p. 35). Whether it was the topic or the theory, Boot et al (2008) added that "a research is an interest stated specifically enough for you to imagine becoming a local expert on it. That doesn't mean you already know a lot about it or that you'll have to know more about it than your teacher does. You just want to know a lot more about it than you do now" (p. 36). The researchers should focus on what interests them, but they should remember that they must eventually show why the work should also interest others (p. 38).

The main goal is to do a study that will give results and conclusions that will help PIs (principle investigators) or any other researcher to evaluate their final proposal draft in the aim to improve it to get the expected fund to carry out the research. After long time of struggle, genre theory from the English Department is to be chosen with its relevant literature to tackle and analyze the grant proposals to achieve the intended goal. 


\section{GENRE ANALYSIS FOR THE ABSTRACTS OF GRANT PROPOSALS}

Triggered by the interesting idea of "different sections of the abstracts of grant proposals" and after searching with different key terms in the library databases, English for Specific Purposes (ESP), with its different genres, and CARS or move-steps for the introduction of research articles are found suitable for this study. This literature is the backbone of the theoretical background and research methodology for this study.

Paltridge and Starfield (2012) state, many of the ESP (English for Specific Purpose) analyses of the discourse structure of texts have been based on Swales' $(1981,1990)$ work in this area. These studies examine for example, the discourse structures of research articles, master's theses and doctoral dissertations, job application and sales promotion letters, legislative documents, the graduate seminar, academic lectures, poster session discussions, and the texts the students read in university courses (see Bawarshi \& Reiff 2010; Crookes 1986; Lin \& Evans 2011; Paltridge 1997; Swales 1990, 2004 for reviews of this work).

One model that has a impact in ESP genre studies is create a research space (CARS) model. This model derives from the work of Swales $(1981,1990)$ and describes the typical discourse structure of the opening section of research articles, that is, the introduction. Swales shows how, in research article introductions, authors establish the territory of their research by showing how it is important and relevant in some way (i.e. move 1: Establishing a research territory). The next move (i.e. move 2: Establishing a niche) indicates the gap in previous research that the author's study aims to address while the third move (i.e. move 3: Occupying the niche) states the purpose of the author's research and how it will fill the gap earlier sections of the introduction have identified. This model has since been applied to the introduction section of other genres such as theses and dissertations (see e.g. Bunton 2002; Pltridge \& Starfield 2007). 


\section{GENRE ANALYSIS FOR THE ABSTRACTS OF GRANT PROPOSALS}

Dudley-Evans (1999) and Paltridge (2002) describe discourse structures of thesis and dissertations written in English. Dudley-Evans describes the typical "IMRAD” (introductionmethods-results-discussion) pattern as being associated with what he terms a "traditional" dissertation. Thompson (1999) further refines this category, dividing traditional dissertations into those that have "simple" and those that have "complex" patterns of organization. A further kind of dissertation is the "topic-based" dissertation. This type of dissertation typically commences with an introductory chapter, which is then followed by a series of chapters that have titles based on sub-topics of the topic under investigation. The dissertation then ends with a conclusion chapter.

Dong (1998) describes doctoral dissertations that are based on a compilation of publishable research articles, which are quite different from other sorts of doctoral dissertations. Particular sections (or part-genres) of theses and dissertations have also been examined such as dissertation acknowledgements, the literature review, discussion sections, and conclusions chapters (see Paltridge 2012a, 2010b; Paltridge \& Starfield 2007; Paltridge et al. 2011a, 2011b; Swales 2004 for reviews and developments of this work). Theses and dissertations, of course, are more than just their discourse structures. They are very complex genres. They can have many readers and, as Pare, Starke-Meyerring, \& McAlpine (2009) point out, many possible readings. Theses and dissertations, further, are part of a much larger genre set (Devitt 2004) that students need command of such as applications for admission, coursework itself, each of which is situated in a particular disciplinary context that influences how the text is produced, and in turn read. The analysis of discourse structures has not been confined to academic genres, however.

Professional genres that have been examined in ESP research include corporate disclosure documents, letters of application, newspaper law reports, and popularized medical 


\section{GENRE ANALYSIS FOR THE ABSTRACTS OF GRANT PROPOSALS}

texts. Much of this work is informed by Bhatia's work such as his (1993) Analyzing Genre: Language Use in Professional Settings and his (Bhatia 2004) Worlds of Written Discourse: A Genre-Based View. Bhatia, and others (e.g. Askehave \& Swales, 2001; Flowerdew, 2002; Swales, 2004) suggest researchers might take a "text-first" or a "context-first" approach to the analysis of a particular genre. That is, they may start by looking at typical discourse patterns in the texts (a text-first approach), or they may commence with an examination of the context of the texts they want to investigate (a context-first approach) and then proceed to examine typical discourse patterns in the text (cf Askehave \& Swales, 2001; Flowerdew 2011; Flowerdew \& Wan 2010; Paltridge 2012; Swales 2004). There is no hard and fast rule on the sequence an analyst might take in carrying out his or her analysis. Rather, it depends on what the researcher is aiming to find out and the overall goal and purpose of the research (p. 350). This theoretical background leads the research to the intended aspect of analysis "textual analysis" or more specifically "genre analysis."

There are many types of "textual analyses." According to Zhou and Sloan (2009), textual approaches could be discourse analysis, narrative analysis, rhetorical analysis, auteur analysis, and generic analysis (pp. 311-316). The latter will be used for this study. Zhou and Sloan (2009) refer to genre analysis as "generic analysis" (p. 314) and classify it as a critical and cultural studies research method. They claim that cultural studies use textual analysis to investigate social phenomena. They explain that a "text" is any form of mediated message. The success and failure of grant proposals in winning the funds is the phenomenon and the focus of the current study. Thus, in this study the text under investigation will be the body of the grant proposals and specifically the "summary or abstract." The meaning of these texts will be revealed by textual analysis. "Grant Proposals" share common textual features and styles that make them a special 


\section{GENRE ANALYSIS FOR THE ABSTRACTS OF GRANT PROPOSALS}

genre that is easily differentiated from other genres. Genres are large groups of texts that have similar elements. Genres could be analyzed according to three parameters: a receiver's response to the text, the stylistic elements of the text, the subject matter within the text (ibid). Stylistic elements of the text will be used to get results from the available data.

In Genre Analysis: English in Academic and Research Settings (1990), Swales provides a detailed definition of genre within the field of English for Specific Purpose:

A genre comprises a class of communicative events, the members of which share some set of communicative purposes. These purposes are recognized by the expert members of the parent discourse community, and thereby constitute the rationale for the genre. This rational shapes the schematic structure of discourse and influences and constrains choice of content and style.

Communicative purpose is both a privileged criterion and one that operates to keep the scope of a genre. In addition to purpose, exemplars of a genre exhibit various patterns of similarity in terms of structure, style, content and intended audience (p. 58). Genres vary in terms of their complexity and rhetorical purpose and the mode or medium through which they are expressed (Jogthong, 2001, p. 9).

As mentioned above, the body of grant proposals have different sections. The summary or the abstract is the most important because it includes almost every aspect of the proposed research. The summary of the proposal constitutes the 'introduction' in later time when the research would be published. The most abundant genre analysis revolved around the "Research Article Introductions" in already published articles (Swales 1981; Jogthong 2001, and Duszak 1994). Most of the studies are comparative studies among different languages. It is worth mentioning them, though, as they are very relevant to the goal of this work. They are relevant 


\section{GENRE ANALYSIS FOR THE ABSTRACTS OF GRANT PROPOSALS}

because "Research Article Introductions" for any research typically represent "abstracts" for any grant proposal. So, it is very easy to say that when an analysis is done for a "Research Article Introduction" taken from any research, the same analysis could be done for an "abstract" taken from a grant proposal. These documents have the same textual features because they belong to the same genre. Most of the studies used a theory that is called "Move Analysis of Research Article Introduction."

These studies focused on "introductions of research articles" that have received the attention of researchers. The reasons for this attention include: first, research articles are a familiar genre to academic writers in virtually all disciplines and fields; second, the research article introduction often sets forth a statement about purpose, method and results, and is thus a conventional structure of organization that can readily be compared (Anthony, 1999); third, research article introductions often give writers difficulty (Swales, 1990); and fourth, research article introductions are often used to determine whether an article will be accepted or rejected for publication (Swales, 1981). In addition to the increased interest in the analysis of 'research article introductions,' Swales (1990) has noted that,

The opening paragraphs require the writer to make some decisions about the amount and type of background knowledge to be included, an authoritative versus a sincere stance, the appropriateness of the appeal to the readership, and the directness of the approach (p. 137).

Swales' works $(1981,1990)$ have had perhaps the most substantial influence on studies on research article introductions. Swales (1981) investigated introductory sections of 48 English research articles, 16 of which were selected from each of the following areas: the "hard" 
sciences, the social sciences and the life and health sciences. He found a consistent pattern in the introduction sections of research articles in which he identified as the Four-Moves Structure: Move 1: Establishing the field by: showing centrality, stating current knowledge, and ascribing key characteristics;

Move 2: Summarizing previous research;

Move 3: Preparing for present research by: indicating a gap, question raising, or extending a finding;

Move 4: Introducing present research by: stating the purpose, and describing present research.

Many studies now use Swales' move analysis to examine the rhetorical structure of research article introductions in various fields, languages and cultures (Lopez, 1982; Cooper, 1985; Crookes, 1986; Swales \& Najjar, 1987). Consequently, Swales’ move analysis has undergone many revisions. For instance, some linguists and researchers (Lopaz, 1982; BleyVroman \& Selinker, 1984; Crookes, 1986) have commented on the difficulties of separating Move 1 (Establishing the field) from Move 2 (Summarizing previous research); others argue that important move options were not included in Swales initial move structure (Jacoby, 1986, 1987; Cooper, 1985).

In his influential book on the field of genre analysis, Genre Analysis: English in Academic and Research Settings (1990), Swales offers a modified version of his original model called Create a Research Space (CARS) to fully capture the rhetorical movement in research article introductions written in English. The newly revised model is comprised of the following move-steps. (The complete structure of the model is presented on page 38 of this thesis): 
GENRE ANALYSIS FOR THE ABSTRACTS OF GRANT PROPOSALS

Move 1: Establishing a territory by: claiming centrality, making topic generalization(s), and reviewing items of previous research;

Move 2: Establishing a niche by: counter-claiming, indicating a gap, question-raising, and continuing a tradition;

Move 3: Occupying the niche by: outlining purposes, announcing present research, announcing principal findings, and indicating research article structure.

Concerning the general applicability of Swales' move analysis, Duszak's (1994) 'Move analysis revisited' is helpful. She stated that Swales' move analysis is flexible to be used to analyze research article introductions in a wide range. She has pointed out that first, move analysis is relevant to the task because it is "conventionally addressed" (p. 229). Thus, it helps the researchers as they have the background information of what can be expected in the introduction of research written by others. Second, in his analysis, Swales (1990) also allowed the possibility of a cycling solution for the ordering of the moves and the flexibility of sequence of the moves. Third, the CARS model can be applied and modified for the analysis of research article introductions across fields. Fourth and finally, Duszak (1994) has supported the potential of the Move formula as "a preliminary indicator of areas of (in) comparability among various writing styles" (p. 299) including cross-cultural comparisons. She mentioned that the model is flexible enough to admit an intervening role of some other parameters of discourse and cultural validity (p. 300).

The other significant study dealing directly with the universal of Swales' CARS model is Anthony's work (1999). In an attempt to evaluate the usefulness of the model in describing the structure of research article introductions, the author employed the model to analyze 12 outstanding research article introductions in the field of software engineering. The CARS model 
GENRE ANALYSIS FOR THE ABSTRACTS OF GRANT PROPOSALS

was chosen for a standard model for many reasons: first, the model has been through several revisions since its conceptions in 1981; second, the model is widely accepted in the field of English Language Teaching (ELT) as realized by a number of references reflected in textbooks on writing; and third, the model is originally based on research into the structure of research article introductions that illustrate many of concepts and techniques used in the field of genre analysis as a whole.

\section{Research Questions and/or Hypothesis}

The methods of formulating the research question and/or the hypothesis used for experiments in natural sciences are somewhat different from the styles used to formulate them in humanities and social sciences. In this study, I would like to make clear the independent and dependent variables as if a scientific experiment is being carried out.

There are important points that should be taken care of in formulating research questions and hypotheses. First, the topic of research should be worth pursuing. Second, the question should not have been fully answered by prior research. Then, formulating a hypothesis to test, if literature points toward specific predictions, is the next step. After that, all the other steps of the scientific inquiry method will be used to test the hypothesis which might include but not limited to choosing the proper research method, finding out results, and carrying out the discussion for these results and conclusions (Kaplan Test Prep. (2015). MCAT Lesson Book, p. 62) and (Kaplan Test Prep. (2015). MCAT Physics and Math Review, p. 366).

A hypothesis should be testable in that: 1 . It can be phrased as an if-then statement; 2. It could have control and experimental treatment groups. 3 . It could be able to measure dependent and independent variables. 4. It should be feasible, interesting, novel, ethical, and relevant. (FINER Method) (MCAT Physics and Math Review, p. 366-367). 
So, formulating the hypothesis follows general formula that manipulating the independent variables results in changes in the dependent variables.

Research Questions for this thesis will be the following:

RQ1: What are the rhetorical patterns (variables) in the text of the proposals that make them persuasive for the panel and win their support?

RQ2: Do all proposals that win grants have high frequency of certain linguistic features that contribute to their success as persuasive messages?

Hypotheses are simply the conversion of research questions into predicative statements.

Proposed Explanation (Hypothesis):

If, most or all proposals have the necessary rhetorical patterns and linguistic features

Experimental Design:

And, by using genre analysis method, we can count these rhetorical patterns and linguistic features (independent variable) in the abstracts of grant proposals (dependent variable) that make them powerful persuasive messages and eventually win the grants.

Prediction:

Then, most or all the abstracts of grant proposals that have rhetorical patterns and linguistic features as persuasive tools will be successful in getting the grants.

\section{Proposed Research (Materials and Methods Section)}

Zhou and Sloan (2009) indicated that collection of accurate data is the key to make observations needed for the analysis to draw conclusions (pp. 17-19). As Dawson (2009) explained, "research methods are the tools that are used to gather and analyze data" (p. 37). The research design that is selected will be determined by the type of the question asked and other feasibility constrains such as time and budget. Different methods have different observation 


\section{GENRE ANALYSIS FOR THE ABSTRACTS OF GRANT PROPOSALS}

techniques, and the appropriate one should be chosen (Zhou \& Sloan, 2009, pp. 18-19). The data or observations should be processed and transformed for qualitative or quantitative analysis ( $\mathrm{p}$. 19). Any analysis uses factors (variables) and their attributes. Communication messages — such as grant proposal abstracts-have both; factors (variables) not related to the text and textual factors (variables) that are directly related to the written text.

Every study has its own controlled factors (independent variables). Buskirk and Gillen (2011) argued that "... a difficulty in many studies is that numerous factors other than those under investigation could affect the outcome. For this reason, scientists seeking to measure the influence of independent variables strive to control other variables" (p. 94). For this work, it was mentioned in the introduction that many factors other than the written texts could affect the persuasive strength of a proposal. These factors should be controlled to increase the validity of this research. These factors were better to be held constant. To come to this end as much as possible, proposals were chosen from the same institution, which was West Virginia University/Health Sciences Center grant proposals

This current qualitative descriptive statistical study used variables just like the inferential statistical analysis study. The more variables used in a research, the more accurate results it gets. Zhou and Sloan (2009) thought that: "Multivariate analysis is an essential step to understand correctly the statistical relationships among different variables" (p. 223). Because of time constraints and limited access to data, this study chose statistical analysis of the length of moves as the main concept of choosing the different variables for this study. The length of moves was expressed as the number (frequency) of sentences. It is worth mentioning that even singlevariable statistical analysis can describe and predict the success of the grant proposals. Zhou and Sloan pointed out that analysis of a single variable at a time is the most common treatment of 


\section{GENRE ANALYSIS FOR THE ABSTRACTS OF GRANT PROPOSALS}

data that lead to description and possible predictions (p. 204). The five moves of the CARS model were used as five numeric variables and the total was used as the cumulative numeric variable. Their attributes were explained carefully in the coding instructions, so it was easy for the coders to measure their frequencies in the chosen texts and complete correctly their coding sheets.

This thesis dealt with the analysis of the content of proposals. It was an attempt to search for textual features that might be a factor in the success of these proposals in getting funded. Therefore, genre analysis was the research method chosen for this paper. It was a method for quantitatively analyzing communication messages. Zhou and Sloan (2009) listed genre analysis (also known as generic analysis) as one type of critical and cultural textual analysis that uses textual approach (p. 306). The texts of grant proposals were used in this study.

The researchers also explained that "by communication messages, we mean any type of communication: texts, visuals, sounds, anything" (p. 123). They added that "text" is any form of mediated message (p. 307). For this work, grant proposals' abstracts were the texts that were used to carry out the analysis. It was expected that this method would answer the questions posed in the introduction. This genre analysis method was used as a stand-alone method to examine these proposals as communication messages. "Either quantitative or qualitative textual analysis methods can be used in generic analysis" (pp. 124 and 317).

This method was preferred for its advantages. It could summarize large bodies of communication messages, there was no need to interact with human subjects, and it could study historical moments and over-time differences (p. 126). Dhoqan et al (1998) listed around ten uses of content analysis in communications and other disciplines. One of them explained that Content analysis could be used to determine the objectives or focus of the writers of certain texts in a 
certain genre which is at the same time the focus of their audience (p. 175). The researcher of this thesis intended to use this fact to get results related to selected scientific topics. Also, the results could tell which schools or specific departments won the lion share from the funded capital. However, genre analysis could also reveal more complex meanings in a communication message such as cultural values or the effects of the messages if used qualitatively along with other methods as survey research or experiments (p. 127).

\section{Specific Methodology of This Study:}

The methodology for this thesis was a replication to the methodology used by the abovementioned studies which analyzed "Research Article Introductions" with some modifications to fit the "abstracts" which were the "sample units" used for this study.

For this study, the following proposal steps were followed to carry out the investigations; data collection process (coding units), procedures, research design, and a brief description of Swales’ (1990) CARS model (coding sheet).

\section{Data Collection}

The "abstracts" as sample units were selected from National Institutes of Health's (NIH) website that had a population of 88 abstracts for West Virginia University for the years 2014 and 2015. The NIH budget is one third of the whole budget for the fiscal year 2015. The Department of Health and Human Services (HHS), including the NIH has had a budget equivalent to the budget of the Department of Defense (DOD), according to slide 9 in the PDF that discusses the estimated SBIR/STTR budgets by agency, for the fiscal year 2015 (SBIR·STTR, n.d.). Both constitutes two thirds ( $\$ 2 \mathrm{~B}$ ) of the whole budgets for the all agencies (ibid). NIH was one of the main funding agencies for West Virginia University. Locke et al. (2014) noted that the 


\section{GENRE ANALYSIS FOR THE ABSTRACTS OF GRANT PROPOSALS}

National Institutes of Health is one of the two largest sources of federal funding in addition to the National Science Foundation (NSF) (p. 166). They added that NIH, which is composed of 27 institutes and centers through which more than $\$ 27$ billion in research funds are distributed, is the primary federal agency that conducts and supports research to improve people's health (e.g. the health of children, men, women, minorities, and seniors, as well as topics related to wellness and lifestyles) (p. 175). All these chosen grants, which were submitted electronically, have already won the fund, so they were successful grants. Health Sciences Pre-Award Grant Office did not allow the researcher to access the local archived grants. Therefore, this was one of the obstacles for this study because grants that failed to win the funds were not accessible. Scientific disciplines are among the fields the researcher is most familiar with. For this reason, medical science proposals were chosen for analysis. An investigation of every sub-field would have been an extremely time-consuming effort beyond the scope of this study and the ability of the researcher.

The author chose this sample because he was an MD carrier. He earned a bachelor's degree in English/Arabic translation. Also, he earned a master's degree in English linguistics and translation. This current work adopted theories from communication and media studies. These degrees made the data relevant to the researcher in the following ways: The jargon of the grant proposals themselves, as medical texts, was familiar to him; grant proposal was a special genre which was an important subfield in English literature; and they were also at the same time communicative persuasive messages which was the concept that linked this current study to the school of media. The other interesting aspect in this work, for the researcher, was that it dealt with the literature of the research itself which was an important topic in epistemology in the Philosophy Department and Statistics Department. This was said because grant proposals 


\section{GENRE ANALYSIS FOR THE ABSTRACTS OF GRANT PROPOSALS}

themselves were special type of research proposals. The unique features of the grant writing techniques were also interesting for the author.

The Pre-Award office at the Health Sciences Center/WVU recommended NIH because the abstracts of West Virginia University's health proposals were publicly accessible at NIH website. The National Institutes of Health's website had Research Portfolio Online Reporting Tools (RePORT). This tool had all the proposals funded by the NIH from all over the nation. According to a tutorial in the RePORT page, this tool could provide what was called frozen data which meant that the data was consistent and would never change. These frozen data were available after the end of each fiscal year. The tool also could narrow the results according to organizational level. West Virginia University, as an organization, narrowed the results to 53 awards for the fiscal year 2015 and 35 proposals for 2014. These two years were the most recent years at the time of writing this paper. The fiscal year 2016 was current at the time of carrying out this research which meant that the data might change, so it was excluded from the process of data collection. These published proposals on the website were successfully funded.

For the selection of the corpus sample from the available population, 20 abstracts were selected by convenient random sampling technique to be analyzed. They made more than $22 \%$ of the available population. It was hoped that this would be helpful to have a representative sample from the population under study. As Anthony (1999) proposed: "Selection of Corpus in previous genre studies gave a general picture of text structure. The articles' corpus was large and from a wide range of sub-disciplines. Studying the whole number of populations would unfortunately limit the time that could be given to individual texts and tend to render the corpus size for a particular discipline rather small” (p. 39). The awards published on the NIH website were grouped according to funding mechanism or activity code. Extramural research awards are 


\section{GENRE ANALYSIS FOR THE ABSTRACTS OF GRANT PROPOSALS}

divided into three main funding mechanisms: grants, cooperative agreements and contracts. A funding mechanism is the type of funded application or transaction used at the NIH. Within each funding mechanism NIH includes programs. Programs can be further refined by specific activity codes. For the purposes of this study, R01 activity code was used to conveniently select the random sample of these awards. The Research Project Grant (R01) was the original and historically oldest grant mechanism used by NIH. The Research Project (R01) grant was an award made to support a discrete, specified, circumscribed project to be performed by the named investigator(s) in an area representing the investigator's specific interest and competencies, based on the mission of the NIH. These kinds of works strictly followed the guidelines and standards of writing all the important elements of the abstracts. Therefore, they were chosen to collect the data needed for the analysis of this study. They were 66 abstracts out of the 88 total population. Then, they were ordered randomly and a number was assigned for each one of them. Then, starting from the abstract number 3 the process of selecting 22 sample units started by selecting the ones that had the order number as the multiples of 3 . That meant that the abstracts that had the order numbers $3,6,9,12,15,18,21,24, \ldots 66$ were chosen as samples for the analysis of this study.

\section{Procedures and Data Analysis}

In analyzing the text for this study, each "abstract" was coded using protocol presented by Swales (1990) as a coding sheet. The sample abstracts were examined in terms of the Movestep sequences and linguistic features. Individual sentences were used as "coding units." The sentences were classified and coded into an appropriate step of the CARS model. Other sentences that did not fit the model would not be coded. The lengths of particular moves were 


\section{GENRE ANALYSIS FOR THE ABSTRACTS OF GRANT PROPOSALS}

noted by counting the number of sentences that belong to that particular move, so an estimate could be made as to where the author has placed emphasis. The results showed the macrorhetorical moves that constituted the informational structure of the "abstracts" and describe the patterns of rhetorical moves made by the grant seekers. In discussing the findings, it was expected to find out measures that could work as indicators that could give feedback and predictions of success for future grant writers.

\section{Research Design}

The pattern of the "abstracts" were coded in terms of six moves that were modified versions of the original moves that were mentioned in the CARS model. This coding was conducted by two coders who were appropriate for the purpose of this study. These coders were trained by the researcher for certain hours in the identification of Swales' (1990) major modified moves in the CARS model (coding sheet). So, by that, they got the appropriate instructions to carry out the coding process.

Before the coders started their coding process, the researcher had done a pretest by choosing an abstract that was not one of the sample units given to the coders. The researcher analyzed this abstract by using the coding instructions and coding sheet to confirm the application and usefulness of the modified model. After that, the coders received separate copies of the sample "abstracts." Then they were asked to mark and identify the moves in each abstract. Inter-coder reliability was determined by comparing the coders' records for each abstract moveby-move, noting agreements and disagreements on the presence or absence of each move and the sequence of moves. If the copies of the same article, which were marked separately by the two 


\section{GENRE ANALYSIS FOR THE ABSTRACTS OF GRANT PROPOSALS}

coders, would be identical in terms of move (or moves) and in their position in the discourse and their sequence of move, they were determined as in agreement. Otherwise, there was disagreement on the structure of moves in that particular sample. Categorization judgments were assessed for inter-rater reliability. The percent agreement was calculated using the formula $\mathrm{A} /(\mathrm{A}+\mathrm{D}) \mathrm{x} 100$ where $\mathrm{A}=$ the number of agreements and $\mathrm{D}=$ the number of disagreements. However, in order to be able to categorize moves and move sequences for all the abstracts, $80 \%$ percent of agreements was required. Thus, in the case of disagreement, a meeting was held by the researcher for the two coders to discuss and agree on an issue. Finally, the frequency of occurrence for each move was counted and categorized for each abstract by the researcher. The final percent of agreement among the coders was $83 \%$.

After the move structures of the abstracts samples were established, the researcher read over the "abstracts," and determined specific steps for each move that have already been identified by the coders and marked on linguistic features and signals found in the abstracts. Then, the information based on the findings was discussed in details.

\section{Create a Research Space (CARS) Model (Used for Coding Instructions)}

Swales' Create a Research Space or the CARS model, that was used to describe rhetorical patterns of research article introductions in previous studies, was used for the abstracts' analyses in this study as well as a coding sheet. The structure of the model was as in Figure 1 below. In writing research article introductions "abstracts for this study," writers typically began by offering the readers a rationale for the research, arguing its significance and locating the research as part of an active, well-established area of study (Move 1 Establishing a territory). They might choose to do this by adopting one or more of the following strategies: first, the writers of the research articles "abstracts for this study" typically opened their introductions 
by making a claim that the area of research was of some significance (Move 1 Step 1 Claiming the centrality).

\section{Move 1 Establishing a territory \\ Step 1 Claiming centrality \\ and/or Step 2 Making topic generalization(s) \\ and/or Step 3 Reviewing items of previous research}

Move 2 Establishing a niche

Step 1 A Counter-claiming

or $\quad$ Step 1 B Indicating a gap

or Step 1 C Question-raising

or Step 1 D Continuing a tradition

Move 3 Occupying the niche

Step 1 A Outlining purpose

or

Step 1 B Announcing present research

Step 2 Announcing principal findings

Step 3 Indicating research article structure
Declining rhetorical effort

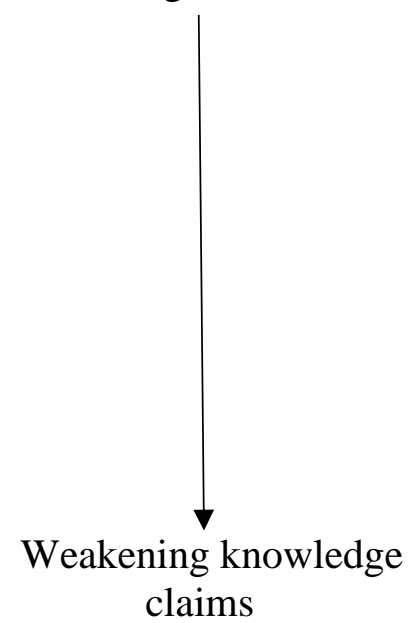

(Swales, 1990: 141)

Figure 1: Swales' (1990) Create a Research Space (CARS) model (Coding Book) 
Some examples of common or typical statements and linguistic signals of centrality claim found in actual research article introductions "abstracts for this study" were presented below. All the following examples in this section were cited in Swales' (1990).

Recently, there has been wide interest in ...

The explication of the relationship between ... is a classic problem of ...

Knowledge of ... has a great importance for...

The study of ... has become an important aspect of ...

The effect of ... has been studied extensively in recent years.

Many investigators have recently turned to...

Second, they made a centrality claim by referring to the current knowledge, practice or phenomena of the topic in general terms (Move 1 Step 2 Making topic generalization). This step could be realized in sentences such as the followings:

The etiology and pathology of ... is well known.

There is now much evidence to support the hypothesis that ...

The ... properties of ... are still not completely understood.

Education core courses are often criticized for ...

$\ldots$ is a common finding in patients with ...

English is rich in related words exhibiting ...stress shifts... (p. 146)

Third, the writers of the research articles "abstracts for this study" further made claim to and describe a "centrality" by reviewing a selective and relevant group of previous studies of the field (Move 1 Step 3 Reviewing items of previous research). 


\section{GENRE ANALYSIS FOR THE ABSTRACTS OF GRANT PROPOSALS}

After claiming and establishing the research territory, the writers tried to establish a niche for their research (Move 2 Establishing a niche) by showing that the previous research is somehow incomplete or had many limitations and weaknesses.

This was commonly done by applying one of the following options: making a bold claim about previous work arguing that it was "misguided" (Step 1A Counterclaiming); indicating that the previous work was insufficient (Step 1B Indicating a gap); questioning previous research (Step 1C Question-raising); or claiming that a new explanation is needed (Step 1D Continuing a tradition). Typically, Move 2 was signaled by terms like: however, nevertheless, yet, unfortunately, but; negative quantifiers such as no, little, none, few; negative verbs or verb phrase such as fail, lack, overlook, not, rarely, ill; negative adjective such as inconclusive, complex, misleading, elusive, scarce, limited, questionable. Some examples of Move 2 are: However, the previously mentioned methods suffer from some limitations ... The first group ... cannot treat ... and is limited to ...

The second group ... is time consuming and therefore expensive, and its ... is not sufficiently accurate.

Both suffer from the dependency on ... (p. 154)

The last move in the CARS model was Move 3 (Occupying the niche) where writers of the research articles claim they will address the problem identified in Move 2. This move outlined the purpose or purposes of the about-to-be reported research (Step 1A Outlining purposes) and described the main features of the present research (Step 1B Announcing present research). Besides Step 1, the obligatory step in Move 3, other options that followed Step 1 are the summary of principal findings of the research (Step 2 Announcing principal findings) and the description of structure or content of the rest of the research article (Step 3 Indicating research 
GENRE ANALYSIS FOR THE ABSTRACTS OF GRANT PROPOSALS

article structure). Some examples of linguistic exponents and signals of Move 3 were listed below:

This paper reports on the results obtained ...

The aim of the present paper is to give ...

In this paper, we give preliminary results of ...

The main purpose of the experiment reported here was to ...

This study was designed to evaluate ...

The present work extends the use the last model ...

We now report the interaction of ...

It was noted, however, that it was possible that the moves might not appear in linear order as outlined in the above model. Crookes (1986) and Swales and Najjar (1987) pointed out that Move 1 Step 3 (Reviewing items of previous research) followed by Move 2 (Establishing a niche) might be repeated several times and the sequence was something like a cycle. The longer the introduction, the more likely this cycling would occur. Swales (1990) has also suggested that cycling might depend on the academic field. There was more cycling in divergent fields such as the social sciences than in the natural sciences and engineering (Swales, 1990).

To identify the order of the moves in the texts the coders were asked to show the numbers that referred to the moves and their order in the second column of the coding sheet. The codes for the moves would be as follows:

1 represented Move 1 Establishing a territory;

2 represented Move 2 Establishing a niche;

3 represented Move 3 Occupying the niche. 
The first column of the coding sheet showed the coded number of each text or sample unit used in the data analysis. The last four columns showed the numbers or the frequency of sentences or the coding unit in each move. The whole coding sheet was as follows:

Table 1: Swales model for the coding sheet

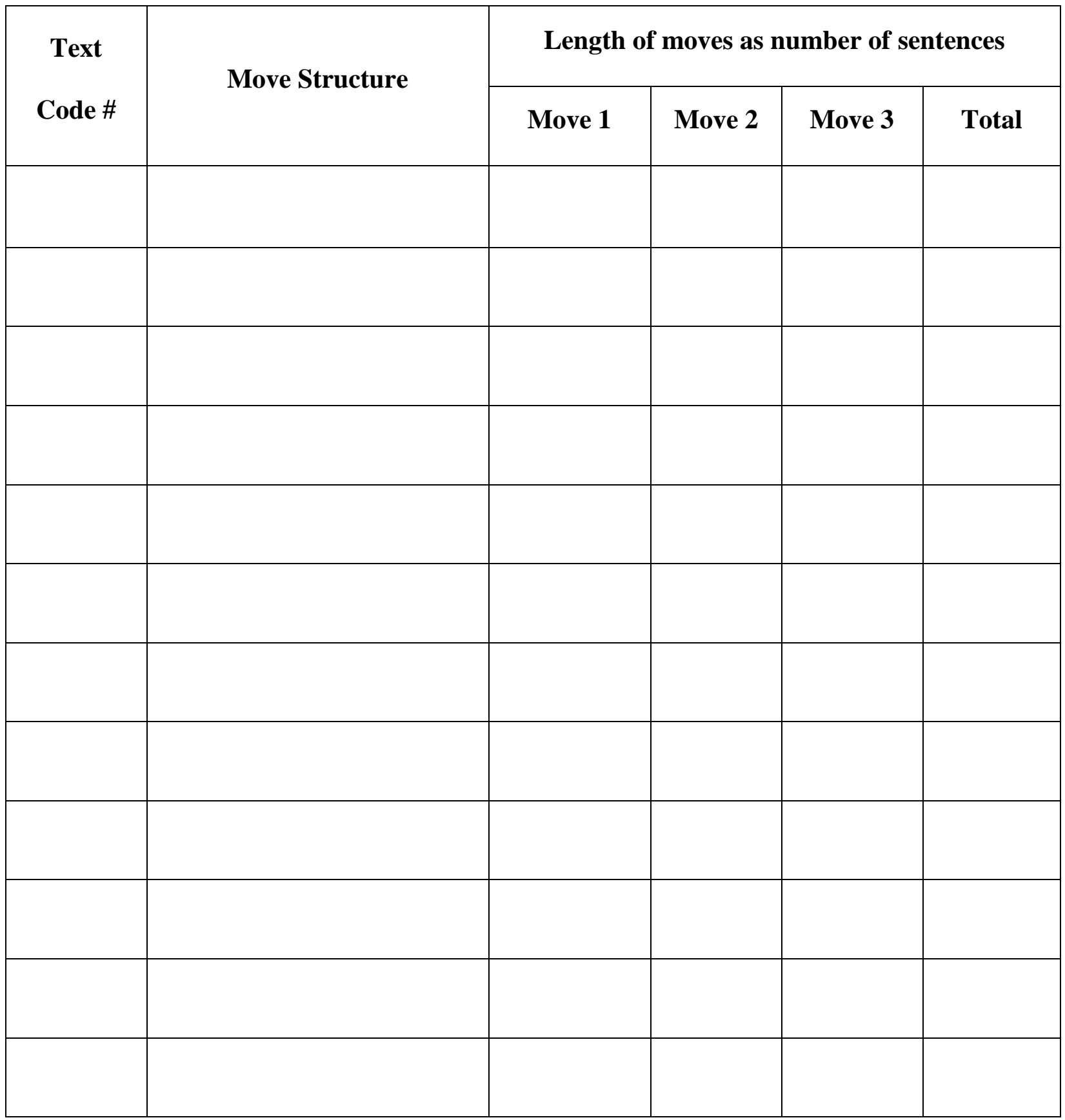


It was mentioned above that Jogthong (2001), in his work on research article introductions, suggested that further studies might also include the analysis of other equally important genres such as grant proposals (p. 90). As this study used grant proposals as its data, the framework of research article introduction's strategy was applied here on the grant proposal analysis.

However, the differences that existed in grant proposals when compared to research article introductions necessitated the need to modify this model to fit the basic sections of the abstracts of the grant proposal.

For these reasons, it was suggested that Swales' model mentioned above would be modified as in the following table:

Table 2: Modified CARS model

\begin{tabular}{|l|l|l|}
\hline Moves & Steps if exist & Content of Moves/Steps \\
\hline Move 1 & & Discuss the need or problem or objective or purpose of the study \\
\hline Move 2 & & The approach that will be taken or other key information from the \\
\hline Move 3 & & How the program will be evaluated \\
\hline Move 4 & & What will be the cost of the work done \\
\hline Move 5 & & What will be the total cost (from all sources) of the work \\
\hline Move 6 & Step 1 & Introduction of the organization \\
\cline { 3 - 4 } & and/or Step 2 & Stating the grant request \\
\cline { 2 - 4 } & and/or Step 3 & Discussing how the project meets the grantmaker's stated goals and \\
& & statement of the project's significance \\
\hline
\end{tabular}




\section{Findings and Results}

It is important to remember that the modifications, that were done to the coding instructions of this study, were planned, suggested, and carried out by the graduate student working on this study. They were not quoted from a peer-reviewed research article or from a well-established theory like the original CARS moves' model suggested by Swale. Therefore, it is not surprising that many of the moves like moves 3,5 , and 6 were not detected in the abstracts as noted in table 3 below. The analysis of the unit samples revealed that some of the suggested added steps were not detected in the abstracts. Table 3 below reflected this absence.

Table 3: Move structures of Twenty Abstracts

\begin{tabular}{|c|c|c|c|c|c|c|c|c|}
\hline \multirow{2}{*}{ Text } & \multirow{2}{*}{ Move Structure } & \multicolumn{6}{|c|}{ Length of moves as number (frequency) of sentences } \\
\cline { 2 - 9 } & & Move & Move & Move & Move & Move & Move & \\
\hline US 1 & 1 & 2 & $\mathbf{3}$ & $\mathbf{4}$ & $\mathbf{5}$ & $\mathbf{6}$ & Total \\
\hline US 2 & $1-2-4$ & 5 & 8 & - & 5 & - & - & 18 \\
\hline US 3 & $2-1-2-4$ & 3 & 2 & - & 4 & - & - & 9 \\
\hline US 4 & $1-4-2-4$ & 4 & 2 & - & 7 & - & - & 13 \\
\hline US 5 & $1-2-1-4-1$ & 7 & 1 & - & 4 & - & - & 12 \\
\hline US 6 & $1-4-2-4-1$ & 3 & 2 & - & 6 & - & - & 11 \\
\hline US 7 & $4-1-4-1-2-4$ & 5 & 1 & - & 8 & - & - & 16 \\
\hline
\end{tabular}


GENRE ANALYSIS FOR THE ABSTRACTS OF GRANT PROPOSALS

\begin{tabular}{|c|c|c|c|c|c|c|c|c|}
\hline US 9 & $4-1-2-4-1$ & 4 & 5 & - & 7 & - & - & 16 \\
\hline US 10 & $4-1-2-4-1-4$ & 5 & 2 & - & 9 & - & - & 16 \\
\hline US 11 & $1-2-4-1-4$ & 5 & 6 & - & 8 & - & - & 19 \\
\hline US 12 & $4-1-2-4$ & 3 & 2 & - & 7 & - & - & 12 \\
\hline US 13 & $4-2-1-4$ & 4 & 5 & - & 9 & - & - & 18 \\
\hline US 14 & $4-2-1-2-4$ & 3 & 2 & - & 8 & - & - & 13 \\
\hline US 15 & $1-2-4$ & 3 & 3 & - & 7 & - & - & 13 \\
\hline US 16 & $4-2-1-4$ & 5 & 4 & - & 6 & - & - & 15 \\
\hline US 17 & $4-1-2-4$ & 4 & 3 & - & 8 & - & - & 16 \\
\hline US 18 & $1-2-4-1$ & 5 & 4 & - & 7 & - & - & 16 \\
\hline US 19 & $4-2-1-4$ & 4 & 3 & - & 8 & - & - & 15 \\
\hline US 20 & $1-2-4$ & 3 & 4 & - & 7 & - & - & 14 \\
\hline Total & & 81 & 66 & & 144 & & & 292 \\
\hline
\end{tabular}

Note: The abbreviation US means Unit Sample which refers to the abstracts used in this study. 
The bar graph and the pie chart below showed the dominance of move 4 over the other two moves 1 and 2 .

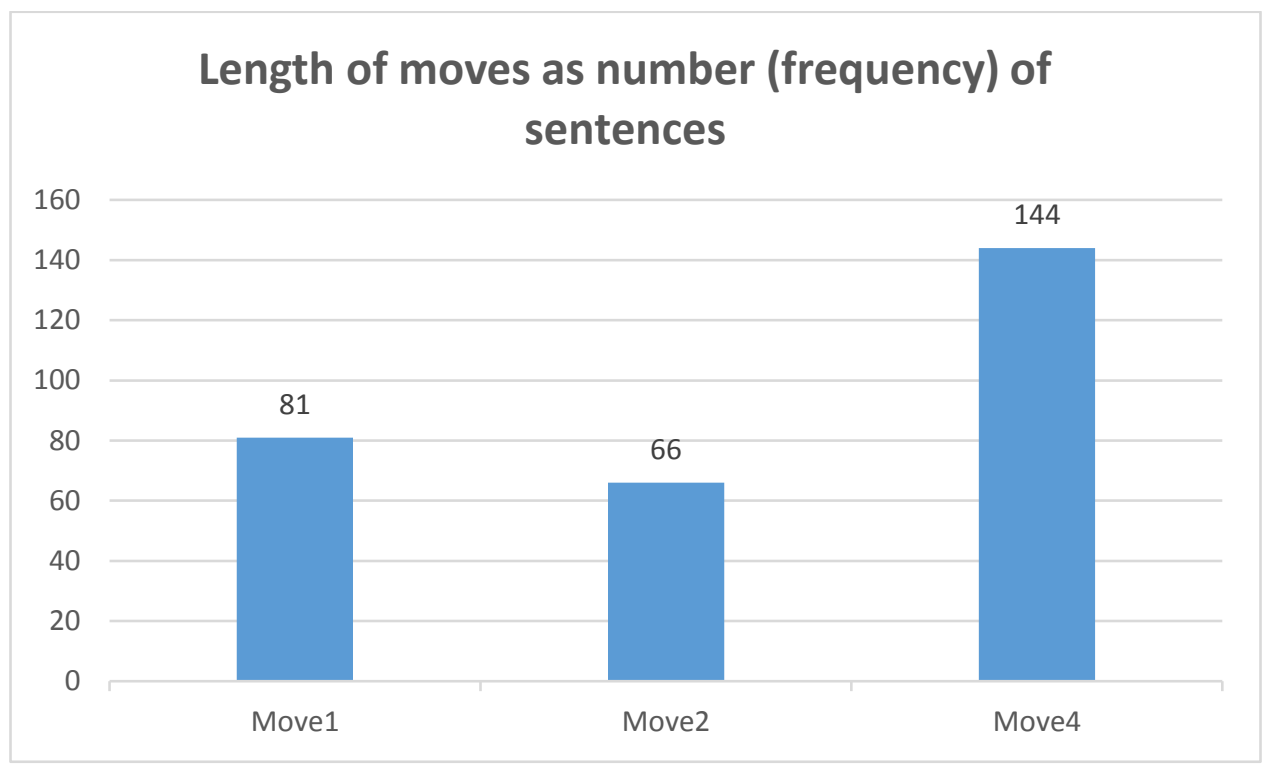

Figure 2: Bar Graph for the moves 1, 2, and 4

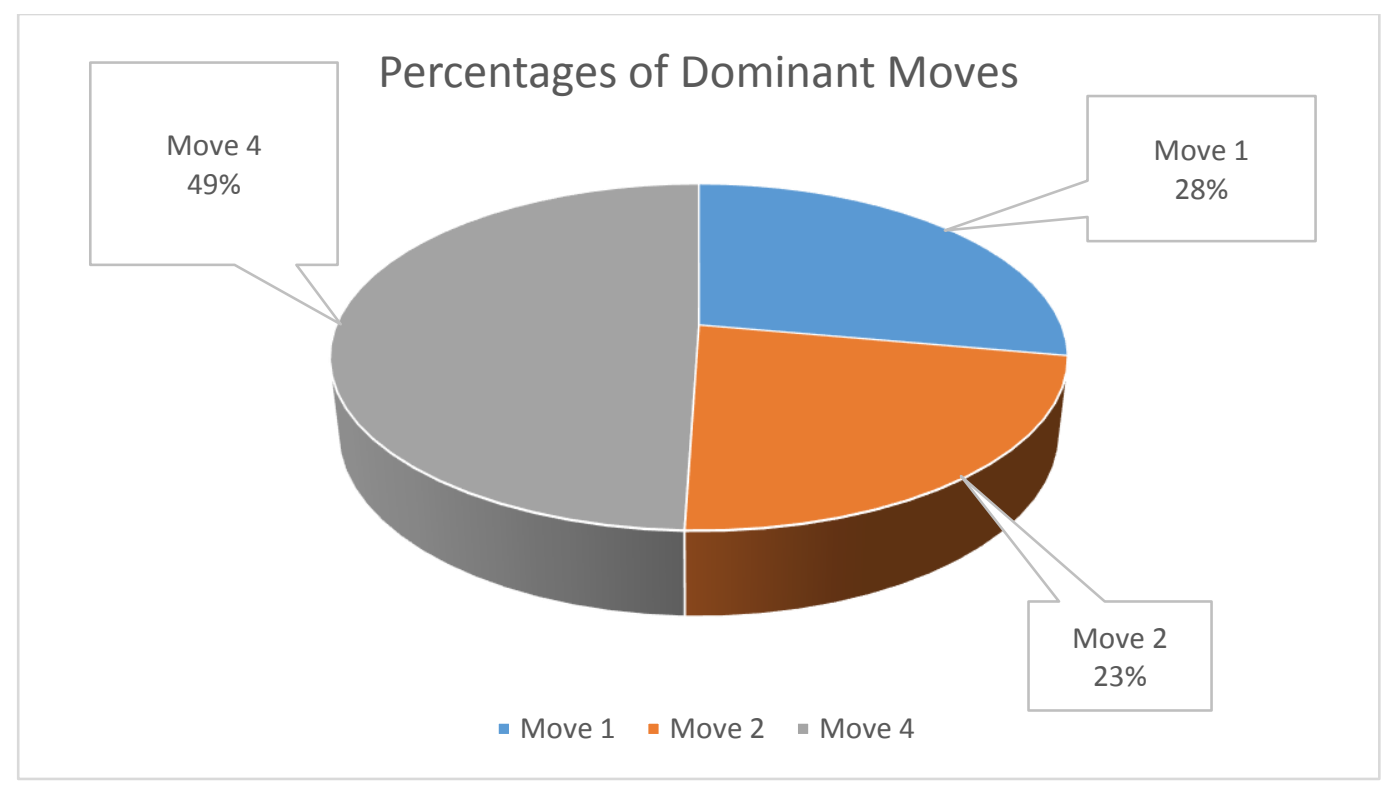

Figure 3: Pie Chart for the moves 1, 2, and 4 
Most of the sentences in the sample units were coded and classified to belong to a certain move. Some of them left non-coded. Table 4 below showed that and also showed the total sentences for each sample unit. The bar graph in figure 4 below illustrated this aspect in a graphical representation.

Table 4: Total Coded and Non-Coded Sentences in each sample unit

\begin{tabular}{|c|c|c|c|}
\hline Text Code \# & Total Sentences & $\begin{array}{c}\text { Total Coded } \\
\text { Sentences }\end{array}$ & $\begin{array}{l}\text { (Difference) } \\
\text { Non-coded } \\
\text { Sentences }\end{array}$ \\
\hline US 1 & 21 & 18 & 3 \\
\hline US 2 & 18 & 16 & 2 \\
\hline US 3 & 14 & 9 & 5 \\
\hline US 4 & 16 & 13 & 3 \\
\hline US 5 & 14 & 12 & 2 \\
\hline US 6 & 15 & 11 & 4 \\
\hline US 7 & 16 & 14 & 2 \\
\hline US 8 & 19 & 16 & 3 \\
\hline US 9 & 17 & 16 & 1 \\
\hline US 10 & 20 & 16 & 4 \\
\hline
\end{tabular}


GENRE ANALYSIS FOR THE ABSTRACTS OF GRANT PROPOSALS

\begin{tabular}{|c|c|c|c|}
\hline US 11 & 22 & 19 & 3 \\
\hline US 12 & 15 & 12 & 3 \\
\hline US 13 & 21 & 18 & 2 \\
\hline US 14 & 15 & 13 & 3 \\
\hline US 15 & 16 & 15 & 2 \\
\hline US 16 & 17 & 16 & 4 \\
\hline US 17 & 18 & 16 & 3 \\
\hline US 18 & 20 & 15 & 37 \\
\hline US 19 & 18 & 14 & 52 \\
\hline US 20 & 17 & 292 & \\
\hline Total & 349 & & 3 \\
\hline
\end{tabular}

Note: The abbreviation US means Unit Sample which refers to the abstracts used in this study. 


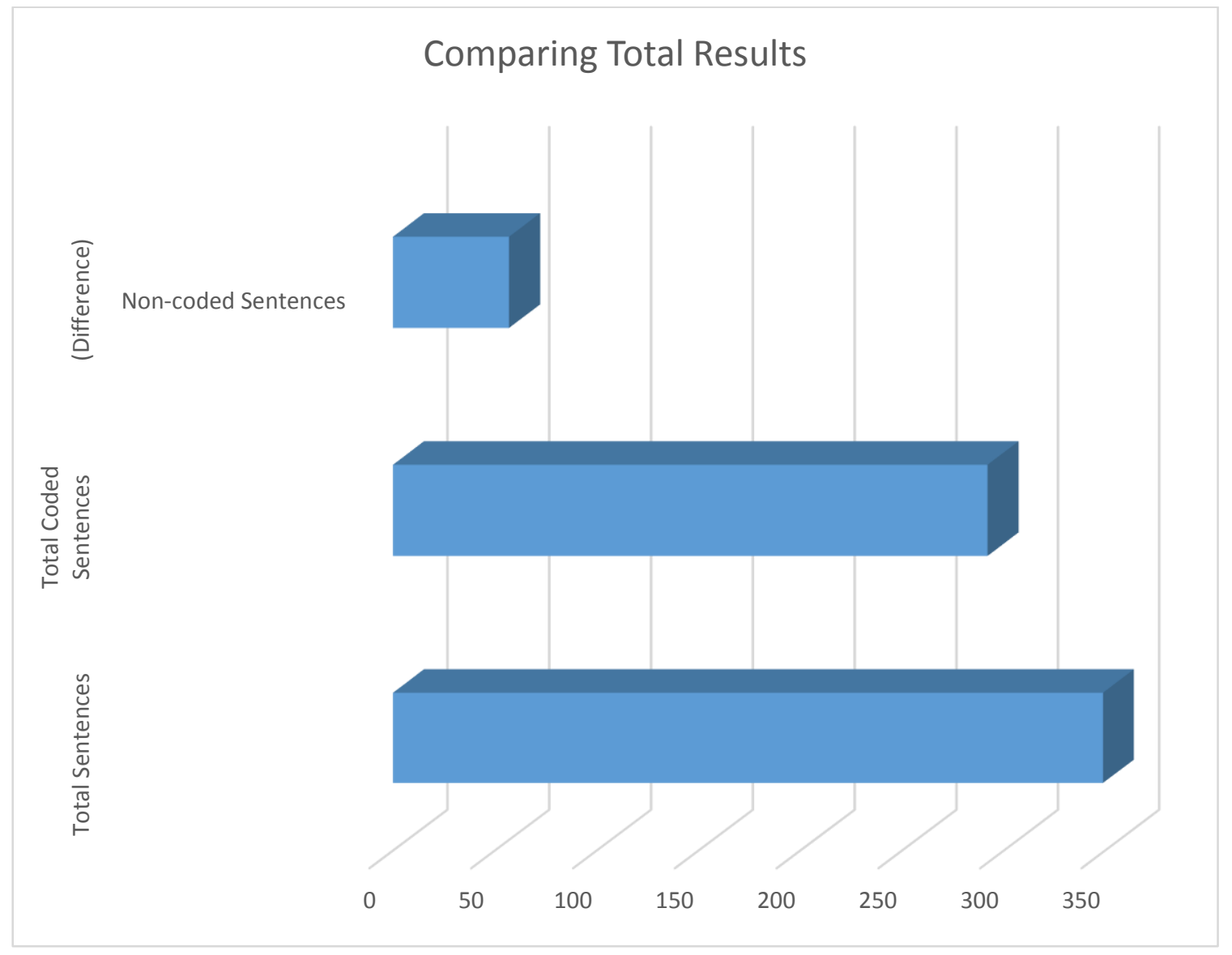

Figure 4: Total Sentences in all sample units, Total Coded Sentences, and Total Non-Coded Sentences in all sample units 
The dominant pattern for the move structure is that most of the abstracts started with move 1 and move 4, as illustrated in table 5 below with the relevant percentages in figure 5 . Table 5: Frequency of Starting Moves in all unit samples

\begin{tabular}{|c|c|}
\hline Move Type & Frequency in all sample units \\
\hline Move 1 & 10 \\
\hline Move 2 & 1 \\
\hline Move 4 & 9 \\
\hline
\end{tabular}

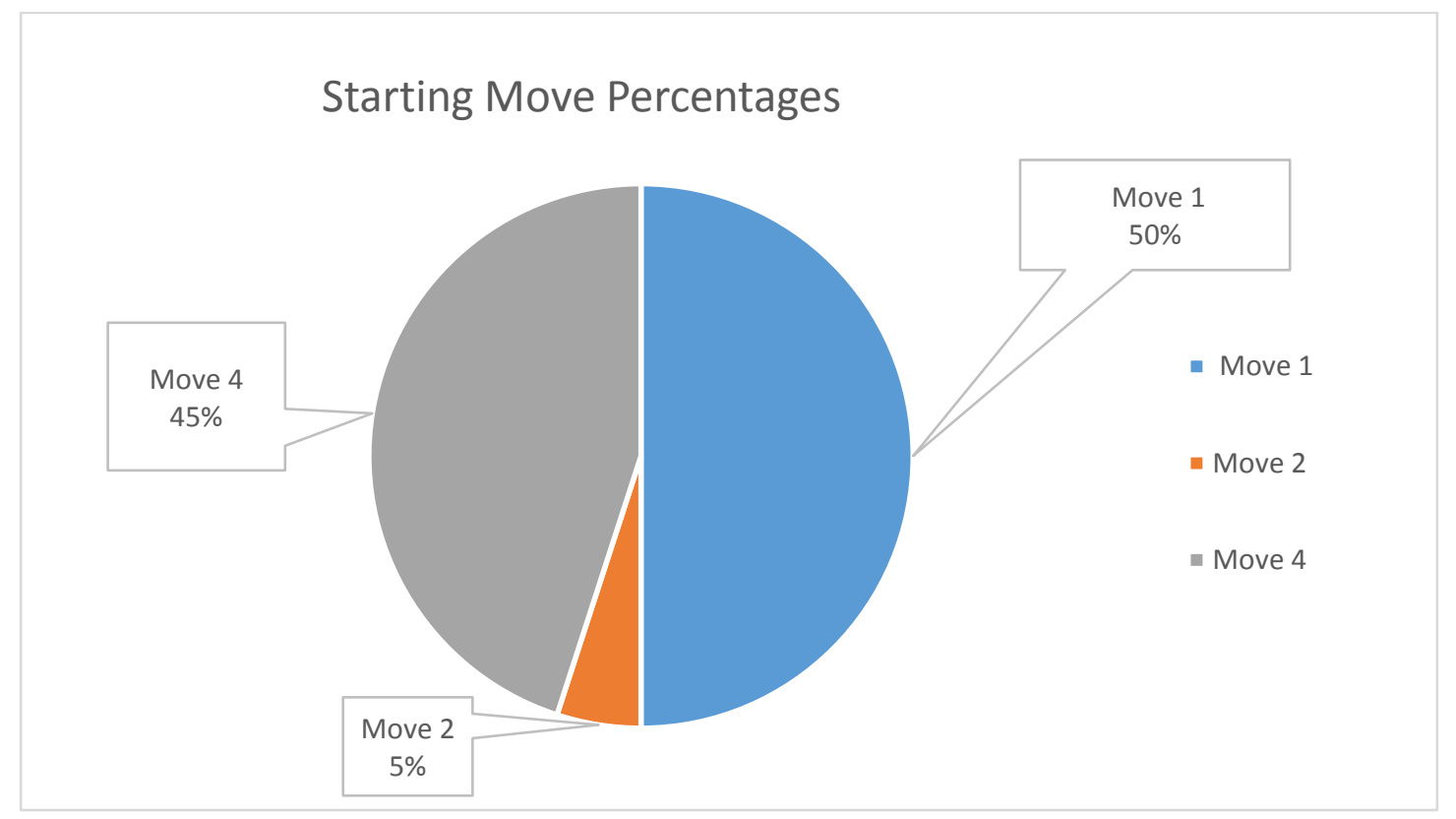

Figure 5: Percentages of Starting Moves in all unit samples 
The findings showed the move structure for most of the abstracts were ending with move 4, as shown in table 5 below. Move 4 made up $75 \%$ as an ending move as shown in figure 6 below.

Table 5: Frequency of Ending Moves in all unit samples

\begin{tabular}{|c|c|}
\hline Move Type & Frequency in all sample units \\
\hline Move 1 & 4 \\
\hline Move 2 & 1 \\
\hline Move 4 & 15 \\
\hline
\end{tabular}

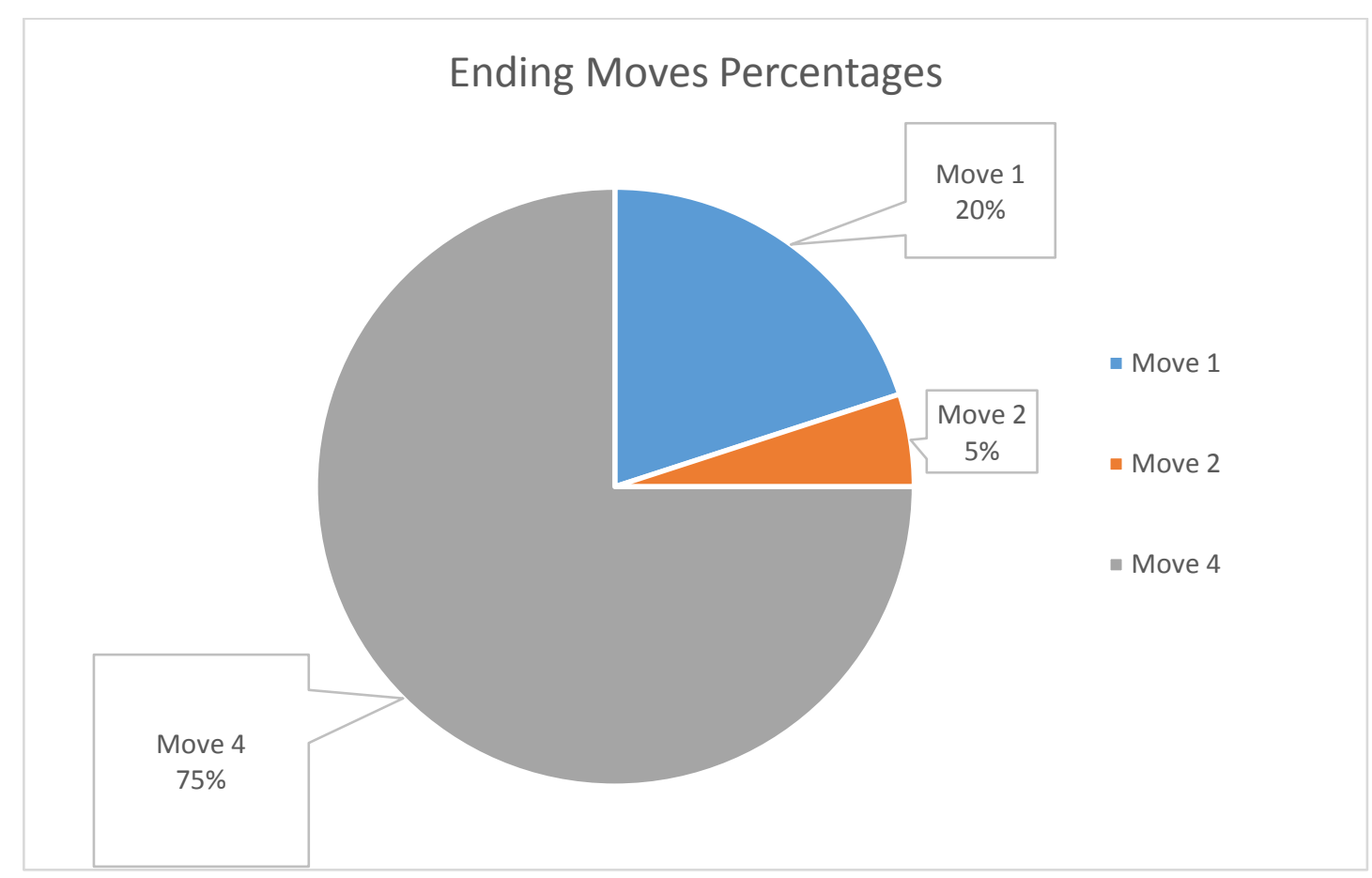

Figure 6: Percentages of Ending Moves in all unit samples 
For the fiscal year 2014, school of medicine had $80 \%$ of the dollar amount as shown in table 6 and figure 7 below.

Table 6: Awards Summary by institution for Fiscal Year 2014

\begin{tabular}{|l|l|l|}
\hline Institution Type & Dollar Amount & Awards \\
\hline Biomedical Engineering & $\$ 433,086$ & 1 \\
\hline Schools of Arts and Sciences & $\$ 477,752$ & 4 \\
\hline Schools of Medicine & $\$ 10,729,519$ & 24 \\
\hline Schools of Pharmacy & $\$ 632,762$ & 2 \\
\hline Schools of Public Health & $\$ 656,388$ & 3 \\
\hline Other & $\$ 447,801$ & 1 \\
\hline Total & $\$ 13,377,308$ & 35 \\
\hline
\end{tabular}

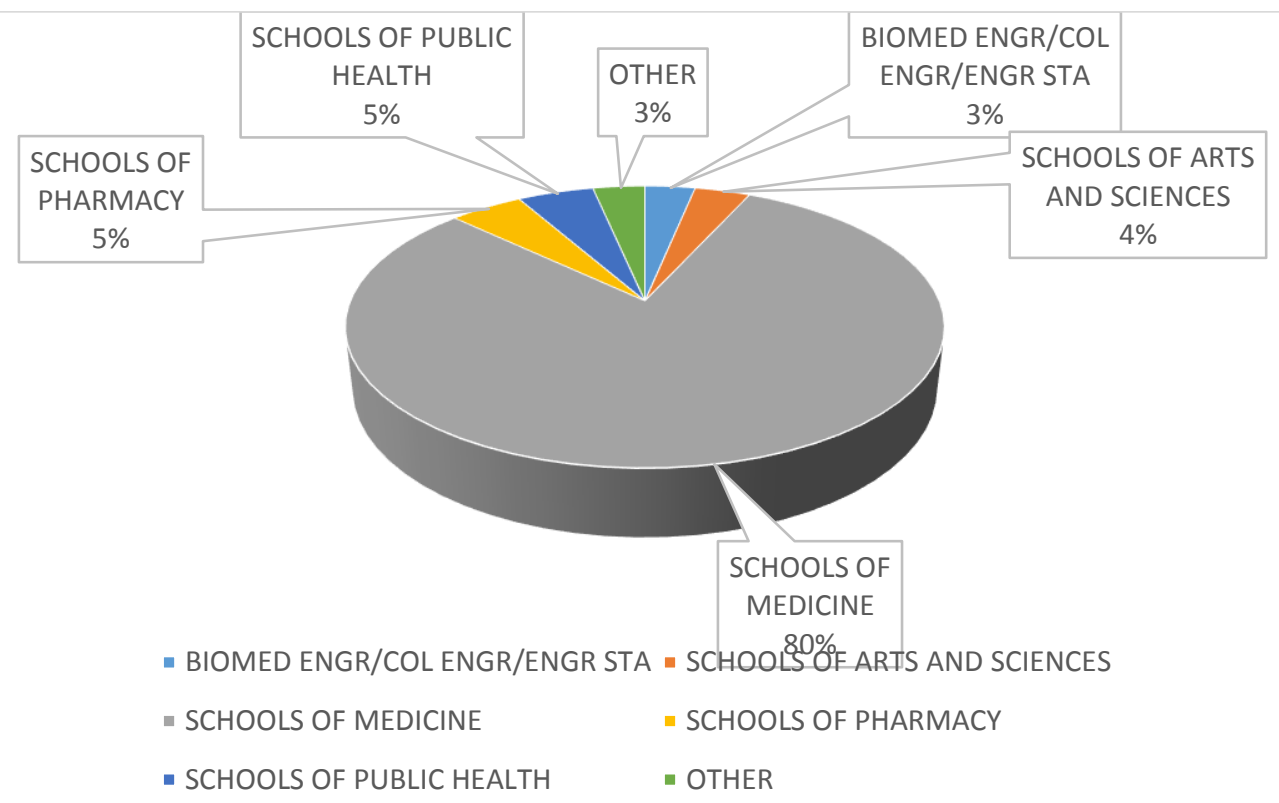

Figure 7: Percentages of Awards Summary by institution for Fiscal Year 2014 
Table 7: Awards Summary by Department for Fiscal Year 2014

\begin{tabular}{|l|l|l|}
\hline Institution Type & Dollar Amount & Awards \\
\hline Biochemistry & $\$ 569,122$ & 2 \\
\hline Biology & $\$ 458,918$ & 2 \\
\hline $\begin{array}{l}\text { Biostatistics \& Biostatistics \& other Math } \\
\text { Sciences }\end{array}$ & $\$ 398,740$ & 1 \\
\hline Chemistry & $\$ 222,000$ & 1 \\
\hline Engineering (All Types) & $\$ 433,086$ & 1 \\
\hline Internal Medicine/Medicine & $\$ 1,317,230$ & 2 \\
\hline Microbiology/Immunology/Virology & $\$ 740,041$ & 2 \\
\hline Ophthalmology & $\$ 988,545$ & 2 \\
\hline Orthopedics & $\$ 74,000$ & 1 \\
\hline Otolaryngology & $\$ 1,562,254$ & 3 \\
\hline Pharmacology & $\$ 632,762$ & 2 \\
\hline Physiology & $\$ 3,691,112$ & 6 \\
\hline Psychiatry & $\$ 174,923$ & 1 \\
\hline Psychology & $\$ 107,752$ & 2 \\
\hline Public Health \& Preventive Medicine & $\$ 1,020,026$ & 5 \\
\hline Radiation-Diagnostic/Oncology & $\$ 538,996$ & 1 \\
\hline Other & $\$ 447,801$ & 1 \\
\hline Total & $\$ 13,377,308$ & 35 \\
\hline
\end{tabular}


For the fiscal year 2015, school of medicine had $69 \%$ of the dollar amount as shown in table 8 and figure 8 below.

Table 8: Awards Summary by Institutions for Fiscal Year 2015

\begin{tabular}{|l|l|l|}
\hline Institution Type & Dollar Amount & Awards \\
\hline Earth Sciences/Resources & $\$ 332,945$ & 1 \\
\hline Schools of Arts and Sciences & $\$ 2,009,398$ & 11 \\
\hline Schools of Medicine & $\$ 11,300,128$ & 32 \\
\hline Schools of Pharmacy & $\$ 1,440,647$ & 4 \\
\hline Schools of Public Health & $\$ 1,261,140$ & 4 \\
\hline Other & $\$ 32,714$ & 1 \\
\hline Total & $\$ 16,376,972$ & 53 \\
\hline
\end{tabular}

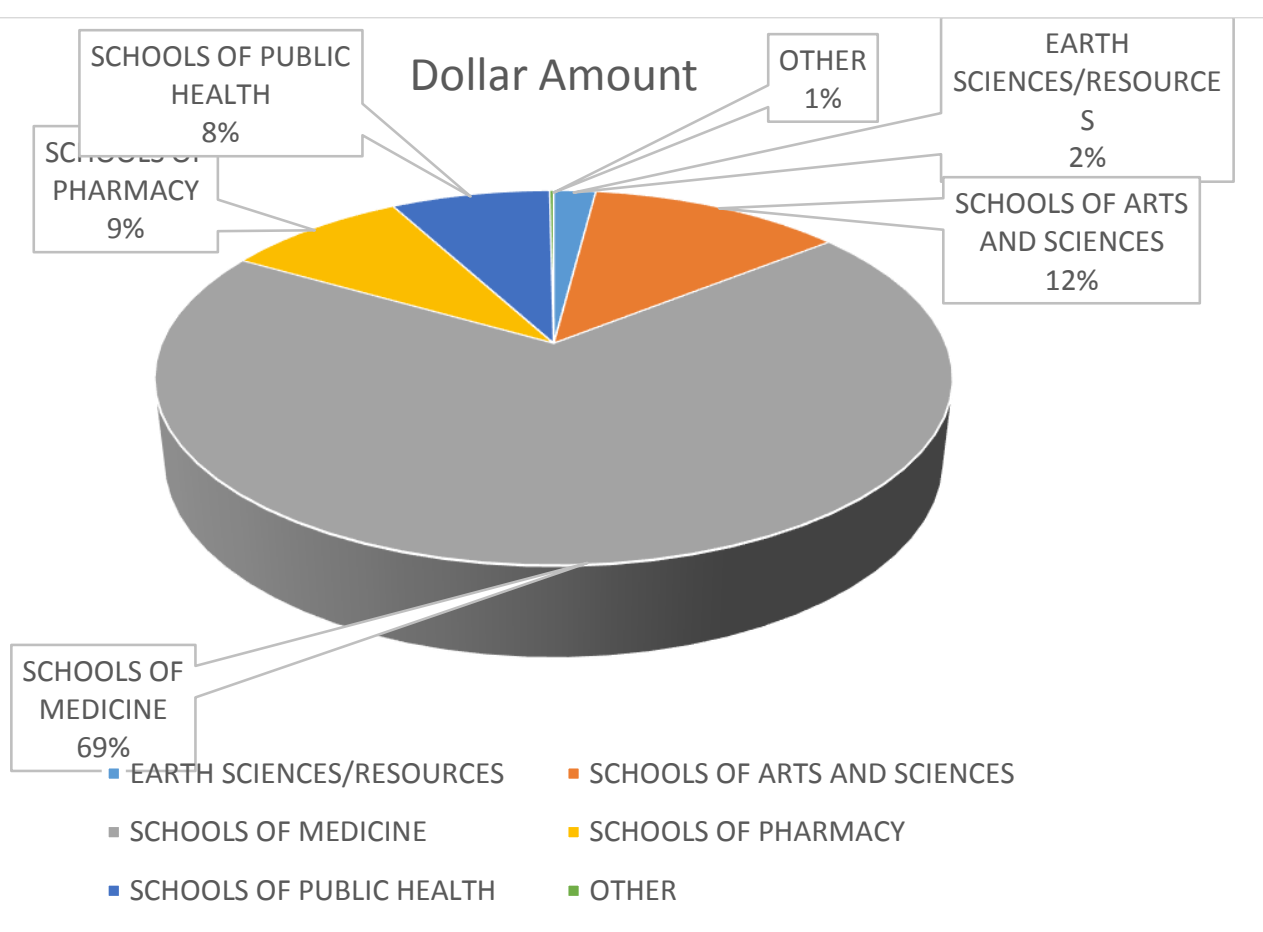

Figure 8: Percentages of Awards Summary by institution for Fiscal Year 2015 
Table 9: Awards Summary by Department for Fiscal Year 2015

\begin{tabular}{|l|l|l|}
\hline Institution Type & Dollar Amount & Awards \\
\hline Biochemistry & $\$ 876,089$ & 4 \\
\hline Biology & $\$ 1,217,482$ & 6 \\
\hline $\begin{array}{l}\text { Biostatistics \& Biostatistics \& other Math } \\
\text { Sciences }\end{array}$ & $\$ 391,641$ & 1 \\
\hline Chemistry & $\$ 695,183$ & 3 \\
\hline Internal Medicine/Medicine & $\$ 1,730,497$ & 3 \\
\hline Microbiology/Immunology/Virology & $\$ 750,122$ & 2 \\
\hline Ophthalmology & $\$ 773,232$ & 3 \\
\hline Orthopedics & $\$ 74,000$ & 1 \\
\hline Other Basic Sciences & $\$ 351,945$ & 2 \\
\hline Otolaryngology & $\$ 436,955$ & 1 \\
\hline Pharmacology & $\$ 1,440,647$ & 4 \\
\hline Physiology & $\$ 4,558,267$ & 9 \\
\hline Psychiatry & $\$ 265,264$ & 1 \\
\hline Psychology & $\$ 620,965$ & 4 \\
\hline Public Health \& Preventive Medicine & $\$ 1,634,994$ & 6 \\
\hline Radiation-Diagnostic/Oncology & $\$ 526,975$ & 2 \\
\hline Other & $\$ 32,714$ & 1 \\
\hline Total & $\$ 16,376,972$ & 53 \\
\hline
\end{tabular}




\section{Discussion and Implications}

For better understanding of the findings, it is worth to repeat the note mentioned above at the beginning of the Finding and Results section. The note above said: "It is important to remember that the modifications, that were done to the coding instructions of this study, were planned, suggested, and carried out by the graduate student working on this study. They were not quoted from a peer-reviewed research article or from a well-established theory like the original CARS moves' model suggested by Swale. Therefore, it is not surprising that many of the moves like moves 3,5 , and 6 were not detected in the abstracts as noted in table 3." The reason for the absence of these moves, according to the author, that they were mentioned in some other sections of the grant proposals submitted to the NIH. The researcher had not expected that at the time of preparing the coding instructions before starting to conduct the study.

In the literature review section, above, the different sections of the grant proposal have been mentioned. They were five core sections as followed: An abstract or executive summary, the statement of need or problem, the project description, an evaluation plan, and a budget. That discussion expressed that these sections were not equal in value and the impression on the part of the reviewers was different from each of these sections. The executive summary (also called an abstract) was described as the most important and it was your reader's first impression of the work. Therefore, the textual features of the "abstract" of the proposals were quantitatively analyzed in this current genre analysis study. It was suggested in this work that the primary points highlighted by Smith and Works (2012) would match the moves of Swale model. However; some modifications were needed with the possibility of adding more moves to end up with a model that was appropriate for the abstracts of the grant applications. Swale model used research article introductions in already published research articles, while this work was trying to 


\section{GENRE ANALYSIS FOR THE ABSTRACTS OF GRANT PROPOSALS}

use grant proposals for data analysis. The context and the circumstances surrounding the production of the writing process of grant proposals were different from that of research article introductions. Smith and Works (2012) presented that the primary points in the executive summary succinctly covered the other four basic sections of the grant proposal. The points were as follows: 1. Discuss the need or problem. 2. The approach that will be taken or other key information from the project description. 3. How the program will be evaluated. 4 . What it will cost. Other points (Moves) that could exist in the abstract are: 5. Introduction of the organization. 6. Stating the grant request. 7. Discussing how the project meets the grant maker's stated goals (p. 74).

Locke et al. (2014) explained the difference between abstracts of research articles and that of grant proposals. He stated "The word abstract normally designate a summary of a larger document. Most published research reports are accompanied by such an abstract. Written in simple past tense, abstracts of that sort are histories of work already accomplished. In contrast, the abstracts of grant proposals are written in the future tense and summarize work that will be done" (p. 211). This reflects the prospective nature of the grant proposals' abstracts.

There have been scholars who talked about the difference between abstracts of grant proposals and the introductions of research articles. Swales (1990) claimed that:

The first real rhetorical test for a grant proposal is the one-page abstract. Indeed, it may represent the biggest hurdle of all; "the abstract that is submitted with the full proposal bears a disproportionate share of responsibility for success or failure" (Locke et al., 1987, p. 121). Unlike a RA's abstract, it is promissory and it need not so obviously reflect proportionately the content of the full proposal. One reason for the latter freedom is that the abstract is likely to be read by a wider group than the specialists asked to 
evaluate the longer document. Since it needs to be written for a wider mix of discourse communities, heavy presumptions of specialized knowledge (and the associated technical vocabulary) tend to be avoided. The abstract also needs to come quickly to the proposed endeavor rather than engage in the kind of space-creating rationale that is typical of RA abstracts (which are typically straightforward condensations of the full version). As a result, abstracts to grant proposals usually begin with the objective or purpose of the study, move on to methodology (procedure and design) and close with a modest but precise statement of the project's significance (p. 187).

This opinion was reflected in the percentages of the starting move which was dominated by move 4 in this study. Move 1 was less common than move 4. Swales (1990) said that it is only in Background (typically a literature review if present) and Description of Proposed research (project), that includes methods, approaches, and evaluation instruments) that the writers tend to assume that the reader-evaluators will be members of their discourse community (ibid, p. 187).

According to a phone call the researcher made to the NIH (National Institutes of Health), a grants' officer said that the instructions told the grant seekers not include the budget information in the abstract section (personal communication, April 20, 2016). In addition, on the website of NIH, the budget request was included under a different tab for the project information (National Institutes of Health (NIH), 2016). The relevance of the project to public health was written under the title "Public Health Relevance Statement" (ibid).

Locke et al. (2014) suggested the typical format required for a proposal abstract that includes the following major elements:

\section{- General purpose}

- Specific goals/aims 
GENRE ANALYSIS FOR THE ABSTRACTS OF GRANT PROPOSALS

\section{- Research design}

- Methods

- Significance (contribution and rationale) (p. 212).

They added that some agencies might also request that the applicant organization (institution) mention the estimated cost (total fund requested) and beginning and ending dates be included in the abstract (p. 212). This latter division of the sections of the abstract must be taken into consideration in the analysis process of the abstracts.

To be very specific about the linguistic features and rhetorical patterns of the abstracts, and to modify the steps in a more precise structure, the researcher used the instructions given by the NIH to the applicants when they wanted to compile their project summary/abstract. National Institutes of Health (NIH) (2016) posted quick links to many aspects related to a form called R\&R (Research \& Related Project Information Form). This form should be submitted to NIH to get the fund. Two of these quick links related directly to the data analyses of this thesis. The first link called Point 7. Project Summary/Abstract. The second link called Project Narrative. In the instructions for the project summary/abstract, the instructions clearly stated the abstract was meant to serve as a succinct and accurate description of the proposed work when separated from the application. They added that the applicant should state the application's broad, long-term objectives and specific aims, referring to the health relatedness of the project (i.e., relevance to the mission of the agency). They asked the grant seeker to describe concisely the research design and methods for achieving the stated goals. They confirmed that the abstract section should be informative to other persons working in the same or related fields and insofar as possible understandable to a scientifically or technically literate reader. They stressed that the grant seeker would avoid describing past accomplishments and the use of the first person. Finally, they 


\section{GENRE ANALYSIS FOR THE ABSTRACTS OF GRANT PROPOSALS}

indicated that the grant writer should make every effort to be succinct. There were also instructions related to the length of the text. They informed that the abstract section must be no longer than 30 lines of text, and follow the required font and margin specifications. They warned that the abstract which exceeded this allowable length might be flagged as an error by the agency upon submission. They remarked that this would require a corrective action before the application would be accepted. The NIH also insisted that grant writers should not include proprietary, confidential or trade secrets in the abstract description section. They explained that if the application were to be funded, the Project Description (abstract) would be entered an NIH database and made available on the NIH Research Portfolio Online Reporting Tool (RePORT, available at http://report.nih.gov) and would become public information. This was the reason that made the abstracts the only accessible data to the investigator working on this thesis.

There were some additional instructions for grant proposals that are related to Career Development. For this, they asked to provide an abstract of the entire application (candidate, environment, and research). They wanted the abstract to include the candidate's immediate and long-term career goals, key elements of the research career development plan, and a description of the research project. All this should not exceed 1 page.

The additional instructions for Training were as follows: Applicant should summarize the objectives, rationale and design of the research training program. Also, applicant should provide information regarding the research areas and scientific disciplines encompassed by the program. There should be a brief description of the level(s) (i.e., undergraduate, predoctoral, postdoctoral, faculty) and duration of the proposed training, the projected number of participating trainees and their anticipated levels of experience. They focused that this section must be no longer than 30 lines of text and must follow the required font and margin specifications. 


\section{GENRE ANALYSIS FOR THE ABSTRACTS OF GRANT PROPOSALS}

Lastly, for Multi-Project, the additional instructions stated that description of the overall project and the other components were required.

NIH enumerated Point 8. Project Narrative in the form mentioned above. They asked to provide Project Narrative in accordance with the announcement and/or agency-specific instructions. They added that for NIH and other PHS agencies applications, no more than two or three sentences should be used to describe the relevance of this research to public health. They cited an example by saying that NIH applicants could describe how, in the short or long term, the research would contribute to fundamental knowledge about the nature and behavior of living systems and/or the application of that knowledge to enhance health, lengthen life, and reduce illness and disability. They expressed that if the application was funded, this public health relevance statement would be combined with the Project Summary/Abstract mentioned above and would become public information. This was true as the researcher of this thesis could see this section under the abstract text section with the following title: Public Health Relevance

\section{Statement.}

There were additional instructions for Training projects. They instructed them to use no more than two or three sentences that described the relevance of their research training program to public health. They asked writers to use plain language in this section that could be understood by a general, non-scientific audience.

The NIH and other PHS allocated a separate form for the Research Plan for the agencies applications. All the other sections of the grant proposal had separate forms too.

Per these detailed descriptions of the needed data in the abstract, the author of this thesis saw some similarities and some differences in comparison and contrast to the Swale's model mentioned above. Therefore, some modifications were done to the coding sheet and coding 
instructions. As stated previously, these modifications were suggested by the writer of this research and were not quoted from a well-established theory. Therefore, some of the moves were not found in the unit samples when the analysis was completed.

To conclude with some answers to the questions posed at the beginning of this work, there are certain rhetorical patterns that act as independent variables that might contribute in strengthening the persuasive power of these abstract when we look at them as a kind of communication messages. This was clear from the domination of move 4 as a starting and ending move in the structure of moves in abstracts. Also, move 1 (Discuss the need or problem or objective or purpose of the study) was prevailing as a starting move. For the second question, it is more difficult to answer accurately, as only the successful grants were investigated. However, it could be said that focusing on the aims (move 4) of the research is one of the most frequent point in the analyzed abstracts in this study.

\section{Limitations}

There were many limitations to bring this work to a satisfactory level. Some of these are mentioned below:

1. Due to failure to access the grants that failed to get the funds, it was not possible to contrast and compare them with the ones which succeeded to be funded. For example, the comparison would be between a proposal that won a grant and a proposal that failed to be funded for the same research team. This could be repeated for many other researchers in the same manner to ensure validity of analysis. Unfortunately, the author couldn't access the awards that failed be funded, so the focus was directed toward the linguistic features of abstracts of successfully funded projects. 
2. The failure to get grants for the same principle investigator led to difficulty in precisely controlling the confounding variables that had possible effects on the results of this study.

3. On the NIH website, it was publicly permissible to access the abstract portion of the grant proposals. It was not possible to see other sections of the grant proposals. This confidentiality limited the ability of the researcher to investigate the relevant information that could help in refining the results of this study.

4. There was difficulty in doing random sampling only. Some of the abstracts were not typical for the analysis of this study, so convenient random sampling was used as it was explained in the data collection step.

\section{Directions for Further Research}

In this thesis, the linguistic characteristics and rhetorical patterns of the abstracts of successfully funded proposals have been explored and discussed. This was done to find a kind of measurements that could be used as indicators for the success of grant proposals written by fund seekers before they submit them to the funding agencies. Other studies could be done to cover other aspects of this interest.

1. Research could explore the linguistic features of other sections of the other four core sections of the grant proposals: the statement of need or problem, the project description, an evaluation plan, a budget, and additional sections or requirements such as the cover letter (Smith \& Works, 2012, p. 73).

2. To get better results, the grant proposals of the same principle investigator which failed to get the fund could be compared with the successful grant proposals for the same principle investigator. 
3. A survey could be done by conducting interviews with interviewees from the funding agencies to study the ethos, pathos, and logos factors. These could reflect other contextual aspects that surround the approval of the project that could not be covered in this thesis. As indicated in The Art and Science of Persuasive Grant Writing: An Empirical Framework for Writing Winning Grants which was a study conducted by Stringfield (2013).

4. Audience analysis or field analysis could also give good results regarding the network of people involved in the whole Funding process of evaluating the project as noted by Moeller and Christensen (2010).

5. Another suggestion might be to investigate the criteria set for reviewers on NIH website which are considered in the determination of scientific and technical merit and give a separate score for each. They are the following:

Significance. Does the project address an important problem or a critical barrier to progress in the field?

Investigator(s). Are the PD/PIs, collaborators, and other researchers well suited to the project? If Early Stage Investigators or New Investigators, or in the early stages of independent careers, do they have appropriate experience and training?

Innovation. Does the application challenge and seek to shift current research or clinical practice paradigms by utilizing novel theoretical concepts, approaches or methodologies, instrumentation, or interventions?

Approach. Are the overall strategy, methodology, and analyses well-reasoned and appropriate to accomplish the specific aims of the project? 
Environment. Will the scientific environment in which the work will be done contribute to the probability of success?

The website mentioned also other contributing factors. These criteria could be quantitatively or qualitatively analyzed and the resulted patterns could be used as an indicator to measure the success rate of the grant proposal before its submission.

6. It is recommended to do a Case Study or a Developmental Study for one Principle Investigator in the Health Sciences Center at West Virginia University or any other medical facility to investigate all of his/her history in general and with regard to winning and failing grant proposals in specific. Taking into considerations that case study would have limitations on the generalizations of the conclusions as they may not be applicable to other cases. However, the conclusions may be applied to cases that have similar circumstances of the already studied case.

7. A Case Study or a Developmental Study also could be carried out on one specific grant proposal whether it fails or succeed in getting the fund. All the steps that it could possibly pass through should be surveyed and analyzed to get some insight about the process in general and the reasons of success or failure in getting the money. The limitations mentioned about case study in point 6 above are applied to this point as well.

8. Colleen M. Lankford, Director of Human Resources, West Virginia University Research Corporation (personal communication, April 25, 2016) said that West Virginia University was getting funds from other federal agencies, other than NIH. The funding agencies were: National Science Foundation, DOE, USDA, DOD R\&D (Department of Defense, Research \&Development), EPA, DHHS (Non-NIH), NASA, 
DOJ, and others. The grants of these agencies could be studied by applying the same methodology of this thesis and then comparative investigations could be done among different results from different agencies.

9. Ms. Lankford mentioned in point 8 above added that the Office of Technology Transfer at West Virginia University had measures of success for research and other sponsored programs. They used the following indicators: Invention Disclosures Filed, US Patent Applications Filed, US Patents issued, License Agreements, Start-Up Companies, and License Royalty and Associated Income. Although these indicators were used for finished projects, they may be used to predict the success for the proposals that are planned to be submitted. The Office of Technology Transfer used also the number of graduate student enrollment as a measure of the success of the sponsored programs (ibid).

10. Ms. Lankford explained that some PIs (Principle Investigators) at the Health Sciences Center at West Virginia University had the responsibility of being professional evaluators for some grant proposals. This job is assigned to them by NIH. A case study could be carried out for one of those professional evaluators to get some more in depth data about how the process of evaluation being carried out and what the used parameters for success are (ibid).

11. Dhoqan et al (1998) listed around ten uses of content analysis in communications and other disciplines. One of them explained that Content analysis could be used to determine the objectives or focus of the writers of certain texts in a certain genre which is at the same time the focus of their audience (p. 175). This niche could be 


\section{GENRE ANALYSIS FOR THE ABSTRACTS OF GRANT PROPOSALS}

used in a future to investigate the selected scientific topics and know the focus of the grants that would possibly the most probable to succeed in getting the fund. 


\section{References}

Anthony, L. (1999). Writing research article introductions in software engineering: How accurate is a standard model? IEEE Transactions on Professional Communication, 42 (1), 38-46.

Bley-Vroman, R. \& Selinker, L. (1984). Research design in rhetorical/grammatical studies: A proposed optimal research strategy. English for Specific Purposes, 84, 1-6.

Booth, W. C., Golomb, G. G., \& Williams, J. M. (2008). The craft of research. Chicago, IL: The University of Chicago Press Chicago \& London.

Buskirk, R., \& Gillen, C. M. (2011). Inquiry in action: Interpreting scientific papers for Campbell Biology. San Francisco, CA: Benjamin Cummings.

Crookes, G. (1986). Toward a validated analysis of scientific text structure. Applied Linguistics, 7, 57-70.

Dadisman, J. A. (2011). English 102: Joining Academic Conversations. Plymouth, MI. Hayden McNeil.

Dawson, C. (2009). Introduction to research methods: A practical guide for anyone undertaking a research project. Oxford, United Kingdom.

Dhoqan, U., Adas, A., \& Abdil Haq, K. (1998). Scientific research: Meaning, Tools, and Styles. Amman, Jourdan. Dar Il Fikir for Printing, Publication, and Distribution.

Duszak, A. (1994). Academic discourse and intellectual styles. Journal of Pragmatics, 21, 291313.

Hornby, A. S. (2005). Oxford advanced learner's dictionary of current English. Oxford New York: Oxford University Press.

Jogthong, C. (2001). Research article introductions in Thai [electronic resource]: genre analysis of academic writing. West Virginia University Libraries. 


\section{GENRE ANALYSIS FOR THE ABSTRACTS OF GRANT PROPOSALS}

Kaplan Test Prep. (2012). MCAT Verbal Reasoning Review Notes. New York, NY: Kaplan Publishing, a division of Kaplan, Inc.

Kaplan Test Prep. (2015). MCAT Lesson Book. Second edition. New York, NY: Kaplan Publishing, a division of Kaplan, Inc.

Kaplan Test Prep. (2015). MCAT Physics and Math Review, Second Edition. New York, NY: Kaplan Publishing, a division of Kaplan, Inc.

Khadka, S. (2014). Geopolitics of Grant Writing: Discursive and Stylistic Features of Nonprofit Grant Proposals in Nepal and the United States. Journal Of Technical Writing \& Communication, 44(2), 141-170. doi:10.2190/TW.44.2.c

Locke, L. F., Spirduso, W. W., \& Silverman, S. J. (2014). Proposals that work: A guide for planning dissertations and grant proposals. Thousand Oaks, CA: Sage.

Lopez, G. S. (1982). Article Introduction in Spanish: A Study in Comparative Rhetoric. Unpublished doctoral dissertation, University of Aston at Birmingham, U.K.

Moeller, R. M. \& Christensen, D. M. (2010). System Mapping: A genre Field analysis of the National Science Foundation's grant proposal and funding process. Technical Communication Quarterly. 19(1), 69-89. Routledge Taylor \& Francis Group.

National Institutes of Health (NIH) (2016). Project Information. Retrieved from https://projectreporter.nih.gov/project_info_description.cfm?aid=9024527\&icde $=0$

Nelson, P. E., Titsworth, S., and Pearson, J. C. (2012). iSpeak: Language is powerful. New York, NY. McGraw-Hill Companies, Inc.

Paltridge, B. (2011, November). Genre and English for specific purposes. Genre Across Borders. Retrieved from http://genreacrossborders.org/research/genre-and-english-specificpurposes 


\section{GENRE ANALYSIS FOR THE ABSTRACTS OF GRANT PROPOSALS}

Paltridge, B., \& Starfield, S. (2012). Handbook of English for specific purposes. Retrieved from http://www.eblib.com

Small Business Administration (SBA) Office of Investment \& Innovation: SBIR-STTR Presentation. n.d. SBIR.STTR. Retrieved from https://www.sbir.gov/about/about$\underline{\text { sbir\#sbir-program }}$

Smith, N. B., \& Works, E. G. (2012). The complete book of grant writing: Learn to write like a professional. Naperville, IL: Sourcebooks.

Stringfield, M. I. (2013). The Art and Science of Persuasive Grant Writing: An Empirical Framework for Writing Winning Grants. West Virginia University Libraries.

Swales, J. M. (1981). Aspects of Article Introductions. Birmingham, U.K.: University of Aston.

Swales, J. M. (1990). Genre Analysis: English in Academic and Research Settings. New York : Cambridge University.

Swales, J. M. \& Najjar, H. (1987). The writing of research article introductions. Written Communication, 4, 175-190.

Zhou, S., \& Sloan, W. D. (2009). Research methods in communications. Northport, AL: Vision Press. 


\section{Appendices}

\section{Appendix I - Coding Instructions}

1. Coder: Simply write your first name.

2. Text Code: Record the number written at the top of each printed abstract (which is the unit sample that was used for the analysis in this study) as the code number.

3. Assign a code number for each sentence according to the following:

1 represents Move 1 Discuss the need or problem or objective or purpose of the study: (sentences that tell why the grant writer plan to carry out the project. These sentences have "because there are $x$ number of cases, it is planned to ..." as an example. These sentences may include the data of people affected by the grant results. Example "according to the local health department ...").

This move (in Swales model called Establishing a territory) may include one or all of the following:

Step 1 Claiming centrality

And/or Step 2 Making topic generalization(s)

And/or Step 3 Reviewing items of previous research

2 represents Move 2 The approach that will be taken or other key information from the project description or methodology (procedure and design): (sentences that tell what the grant seeker is going to do). Such sentences state the goals with the infinitive "to" and list the objectives as beginning with the word "by," as for example "to accomplish A by doing a,b,c, and d." Also you can code this move 1 for sentences that read the outcomes (what will change?).

This move (in Swales model called Establishing a niche) may include one or all of the following:

Step 1A Counter-claiming

Or Step 1B Indicating a gap

Or Step 1C Question-raising

Or Step 1D Continuing a tradition

3 represents Move 3 How the program will be evaluated

4 represents Move 4 Occupying the niche. This step may include one or all of the following:

Step 1A Outlining purposes

Or Step 1B Announcing present research

Step 2 Announcing principle findings

Step 3 Indicating research article structure.

5 represents Move 5 What will be the total cost (from all sources) of the work 6 represents Move 6 
Step 1 Introduction of the organization And/ or Step 2 Stating the grant request (from this specific funder) And/or Step 3 Discussing how the project meets the grantmaker's stated Goals and statement of the project's significance

4. If it seems that none of these above mentioned code numbers could be assigned to a certain sentence(s), do not force yourself to read one of the code numbers into it; instead, leave the sentence and don't try to code it.

5. After you assign the codes for the codeable sentences, please, identify the narrative order of the moves in each abstract. As a coder, you need to show the numbers that refer to the moves and their order in the second column of the coding sheet which is labeled move structure.

6. You could use the columns labeled Move 1 through 5 to show the numbers (frequency) of sentences for each move. 
GENRE ANALYSIS FOR THE ABSTRACTS OF GRANT PROPOSALS

\section{Appendix II - Coding Sheet}

Coder

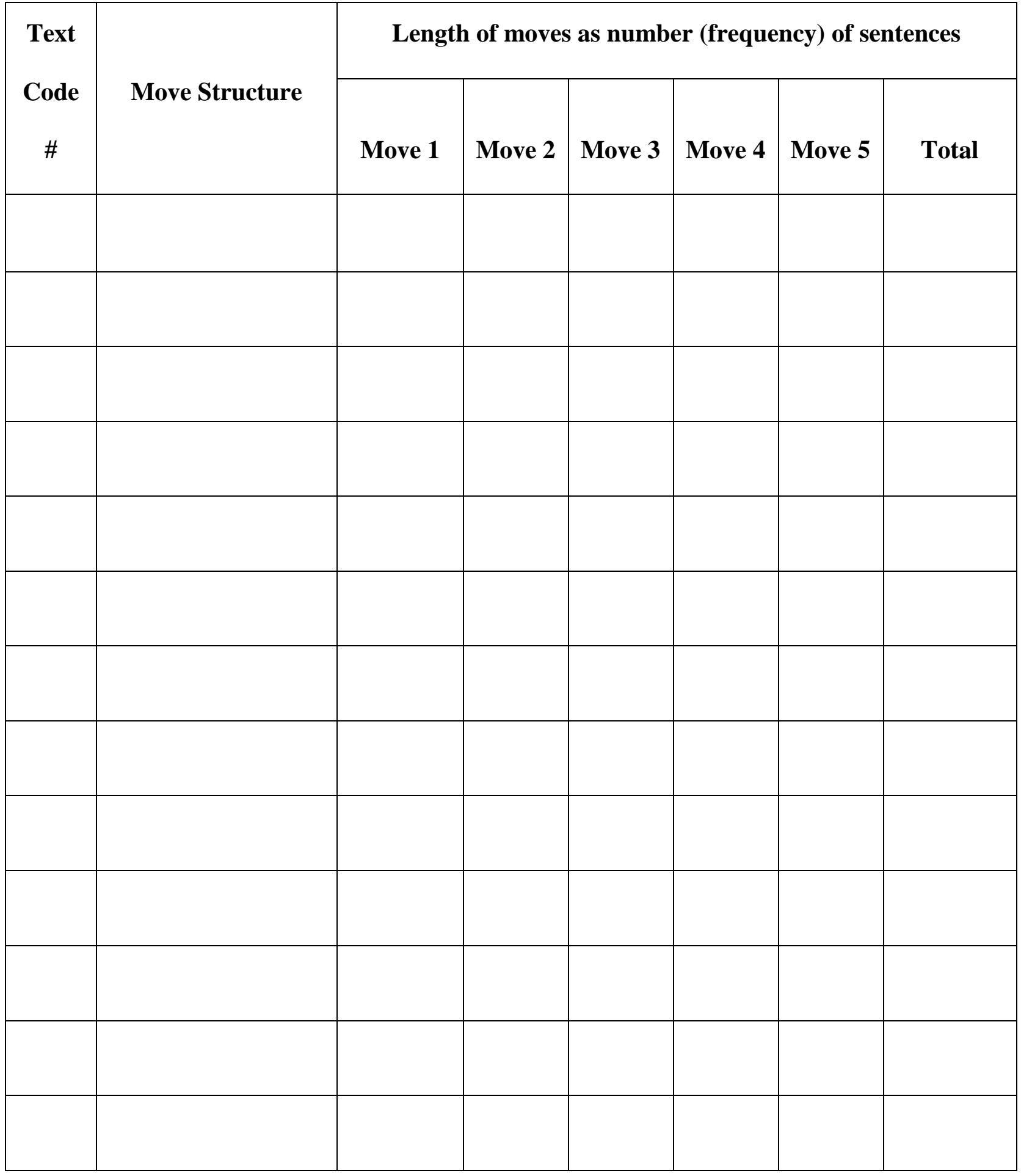




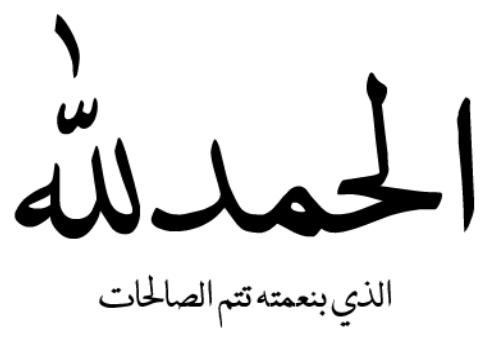

\section{Praise to God}

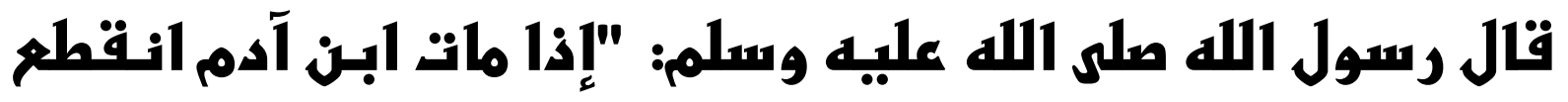

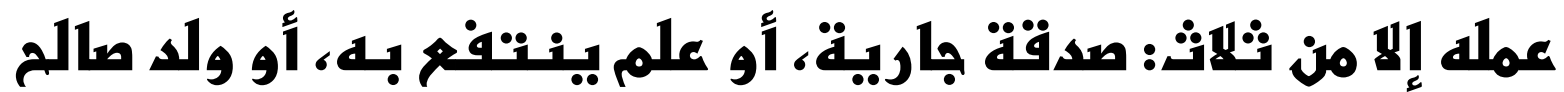

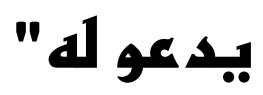

The Messenger of Allah (

"When a man dies, his deeds come to an end except for three things: Sadaqah Jariyah (ceaseless charity); a knowledge which is beneficial, or a virtuous descendant who prays for him (for the deceased)." 